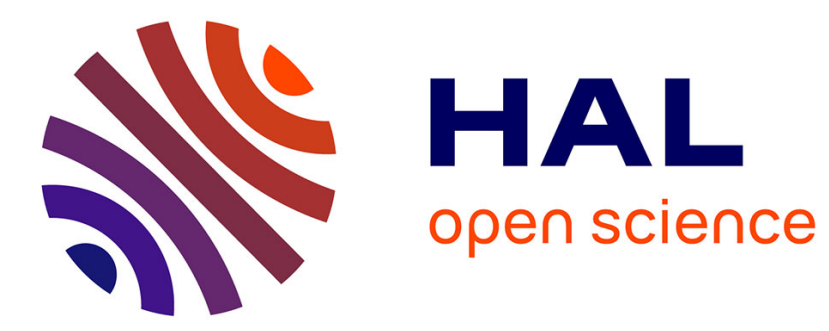

\title{
Stratospheric temperatures and tracer transport in a nudged 4-year middle atmosphere GCM simulation
}

\author{
M. K. van Aalst, J. Lelieveld, B. Steil, C. Brühl, P. Jöckel, M. A. Giorgetta, \\ G.-J. Roelofs
}

\section{- To cite this version:}

M. K. van Aalst, J. Lelieveld, B. Steil, C. Brühl, P. Jöckel, et al.. Stratospheric temperatures and tracer transport in a nudged 4-year middle atmosphere GCM simulation. Atmospheric Chemistry and Physics Discussions, 2005, 5 (1), pp.961-1006. hal-00301035

\section{HAL Id: hal-00301035 \\ https://hal.science/hal-00301035}

Submitted on 21 Feb 2005

HAL is a multi-disciplinary open access archive for the deposit and dissemination of scientific research documents, whether they are published or not. The documents may come from teaching and research institutions in France or abroad, or from public or private research centers.
L'archive ouverte pluridisciplinaire HAL, est destinée au dépôt et à la diffusion de documents scientifiques de niveau recherche, publiés ou non, émanant des établissements d'enseignement et de recherche français ou étrangers, des laboratoires publics ou privés. 


\section{Stratospheric temperatures and tracer transport in a nudged 4-year middle atmosphere GCM simulation}

M. K. van Aalst ${ }^{1}$, J. Lelieveld ${ }^{2}$, B. Steil ${ }^{2}$, C. Brühl ${ }^{2}$, P. Jöckel ${ }^{2}$, M. A. Giorgetta ${ }^{3}$, and G.-J. Roelofs ${ }^{1}$

${ }^{1}$ Institute for Marine and Atmospheric Research (IMAU), Utrecht, The Netherlands

${ }^{2}$ Max Planck Institute for Chemistry, Mainz, Germany

${ }^{3}$ Max Planck Institute for Meteorology, Hamburg, Germany

Received: 6 January 2005 - Accepted: 12 February 2005 - Published: 21 February 2005

Correspondence to: M. K. van Aalst (maarten.vanaalst@xs4all.nl)

(C) 2005 Author(s). This work is licensed under a Creative Commons License.

Stratospheric

temperatures and transport in a nudged

GCM

M. K. van Aalst et al.

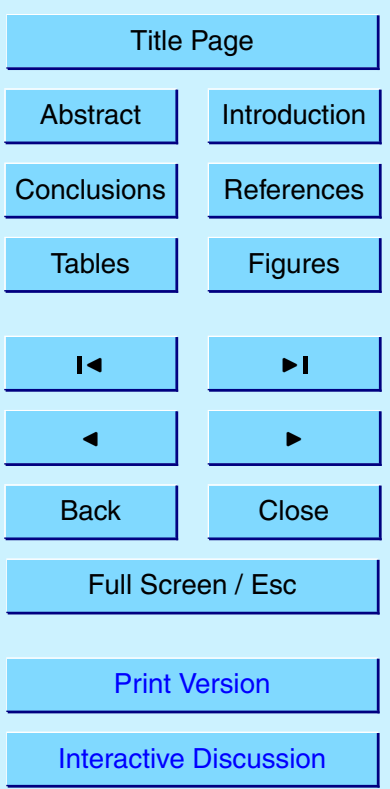




\section{Abstract}

We have performed a 4-year simulation with the Middle Atmosphere General Circulation Model MAECHAM5/MESSy, while slightly nudging the model's meteorology in the free troposphere (below $113 \mathrm{hPa}$ ) towards ECMWF analyses. We show that the

5 nudging technique, which leaves the middle atmosphere almost entirely free, enables comparisons with synoptic observations. The model successfully reproduces many specific features of the interannual variability, including details of the Antarctic vortex structure. In the Arctic, the model captures general features of the interannual variability, but falls short in reproducing the timing of sudden stratospheric warmings. A detailed comparison of the nudged model simulations with ECMWF data shows that the model simulates realistic stratospheric temperature distributions and variabilities, including the temperature minima in the Antarctic vortex. Some small (a few K) model biases were also identified, including a summer cold bias at both poles, and a general cold bias in the lower stratosphere, most pronounced in midlatitudes. A comparison of tracer distributions with HALOE observations shows that the model successfully reproduces specific aspects of the instantaneous circulation. The main tracer transport deficiencies occur in the polar lowermost stratosphere. These are related to the tropopause altitude as well as the tracer advection scheme and model resolution. The additional nudging of equatorial zonal winds, forcing the quasi-biennial oscillation, sig-

\section{Introduction}

Van Aalst et al. (2004a) applied a Newtonian relaxation technique in a middle atmosphere (MA) general circulation model (GCM) to nudge the model towards meteorological analyses for a particular period. Van Aalst et al. (submitted, 2004b) ${ }^{1}$ showed

\footnotetext{
${ }^{1}$ Van Aalst, M. K., Lelieveld, J., Steil, B., Brühl, C., Jöckel, P., Kirchner, I., and Roelofs, G.-J.: The 2002 Antarctic vortex split in a nudged middle-atmosphere GCM, Geophys. Res. Lett.,
}

ACPD

5, 961-1006, 2005

\section{Stratospheric temperatures and transport in a nudged GCM}

M. K. van Aalst et al.

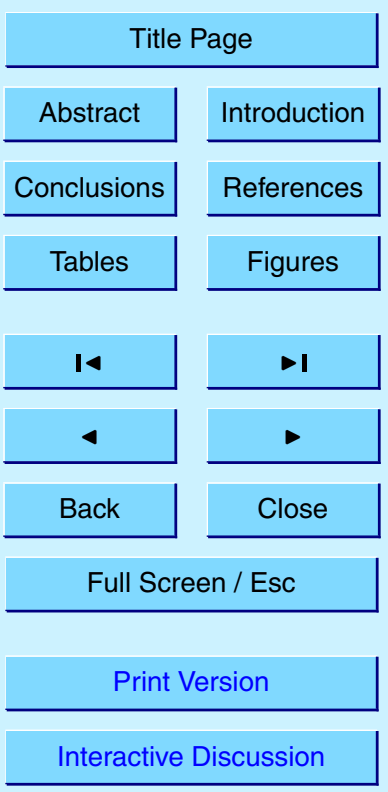

EGU 
that their GCM, MAECHAM5 (ECHAM5 is the European Centre Model, Hamburg version 5), reproduces the unprecedented Antarctic vortex split in September 2002 when nudging only the lower part of the model (below $113 \mathrm{hPa}$ ) towards analyses of the European Centre for Medium-range Weather Forecasts (ECMWF). They noted that this 5 result offers good prospects for direct comparisons of model results with synoptic observations, while leaving the middle atmosphere entirely free, as in the free-running GCM.

With the current simulations we have tested this setup for a 4-year period to examine temperature distributions and tracer transports in the stratosphere. While these sim10 ulations employ the a version of MAECHAM5/MESSy (MESSy is the Modular Earth Submodel System; see http://www.messy-interface.org) without comprehensive chemistry, our analysis addresses the potential to apply this nudging technique in a GCM with fully coupled chemistry (e.g. Steil et al., 2003; Manzini et al., 2003). Our focus is primarily on (i) the degree to which polar dynamical processes approximate reality, including the occurrence and timing of sudden stratospheric warmings and the location of the polar vortex; (ii) the accuracy of simulated stratospheric temperatures, particularly in the polar regions, for instance to realistically represent Polar Stratospheric Cloud (PSC) conditions; and (iii) large-scale tracer transports (diagnosed by comparing modeled methane and water vapor fields with satellite observations). While we leave most of the middle atmosphere entirely free, we also force a realistic quasi-biennial oscillation (QBO) by applying a weak nudging to the stratospheric equatorial zonal wind. The QBO nudging allows to include the QBO and its effects on temperature and transport even though the vertical resolution used here is too coarse to simulate the QBO directly (Giorgetta et al., 2002). Furthermore, this assimilation, which follows observed time series, also allows the synchronization of the QBO with the weather assimilated in the troposphere and with prescribed sea surface temperatures and ice concentrations.

Our simulations can be compared to more regular assessments of GCM performance, which usually focus on averages and variabilities over longer time periods, submitted, 2004b.

\section{ACPD}

5, 961-1006, 2005

\section{Stratospheric temperatures and transport in a nudged GCM}

M. K. van Aalst et al.

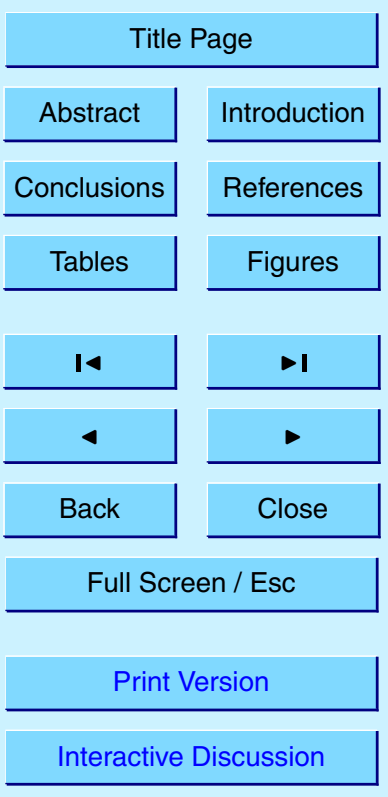


comparing at least 10-15 years of output from free-running GCMs with meteorological reanalysis datasets and/or climatologies based on a similarly long record of measurements. This has several drawbacks. First, the atmospheric background chemical conditions are not constant due to changing emissions, particularly of long-lived green5 house gases and chlorofluorocarbons that affect stratospheric ozone and dynamics. Steady-state "time slice" GCM simulations (e.g. Steil et al., 2003; Manzini et al., 2003) do not capture these trends, and cannot be compared to sufficiently long sets of atmospheric data (particularly when the primary interest of the GCM simulations is to study processes that are sensitive to the changes induced by the changes in atmo10 spheric composition). An alternative is to use so-called transient GCM experiments (e.g. Austin, 2002), which explicitly include the changing emissions. While these simulations are valuable to analyze long-term trends, a difficulty is that the transient runs are associated with internal, e.g. interannual variability, complicating detailed comparisons with measurements. Furthermore, for many processes and parameters long measurement records are not available, thus precluding a statistical analysis. Finally, it may be desirable to simulate particular measurement campaigns.

The nudging applied here provides a simple tool to assess the performance of a regular GCM (in this case including the middle atmosphere, potentially also including coupled chemistry) while retaining the full consistency and flexibility of the climate model, as it is also used for free-running climate simulations. While it is possible to apply the nudging technique in the entire domain for which analyses are available (as in Van Aalst et al., 2004a), it is desirable to limit the nudging to the extent possible (as in Van Aalst et al., submitted, 2004b ${ }^{1}$ ) to prevent that model errors are masked by artificial tendencies, and also because in some cases the model may actually outper-

form the analyses, particularly when the model is applied with coupled chemistry, and in areas where observations are sparse (in most of the middle atmosphere).

Section 2 briefly describes the MAECHAM5/MESSy model and the setup of our nudged simulations. Section 3 discusses the analyses and observations used in our comparisons. Sections 4 and 5 evaluate the main results for temperatures and tracer
ACPD

5, 961-1006, 2005

\section{Stratospheric temperatures and transport in a nudged GCM}

M. K. van Aalst et al.

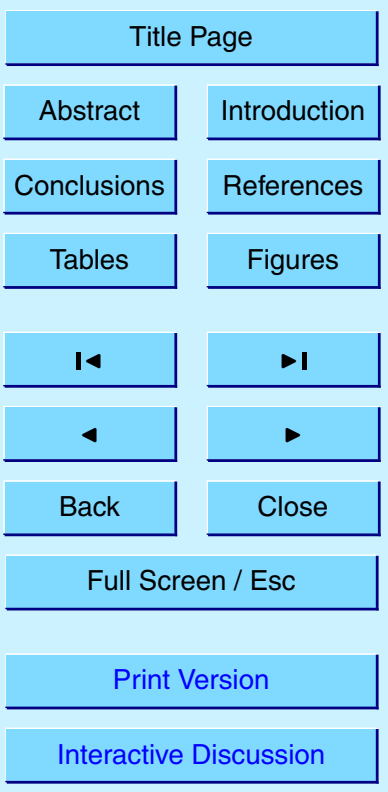




\section{Model description and nudging}

5, 961-1006, 2005

MAECHAM5/MESSy is the middle atmosphere configuration of the ECHAM5 GCM described by Roeckner et al. (2003), with extensions from the Modular Earth Sub5 model System (MESSy) (Jöckel et al., 2004). MAECHAM5 includes all processes of the tropopheric ECHAM5 and computes additionally the momentum deposition in the middle atmosphere by the dissipation of a vertically propagating spectrum of gravity waves of tropospheric origin. The gravity wave scheme has been implemented in the previous model version, MAECHAM4 (Manzini and McFarlane, 1998; Manzini et al., 1997) for the previous model version (MAECHAM4). The latter has been used extensively for a variety of studies, including those with coupled chemistry (e.g. Steil et al., 2003; Manzini et al., 2003). MAECHAM5 has been applied by Giorgetta et al. (2002), who showed that the model (in the 90-level configuration) successfully simulates the QBO, and Manzini et al. (submitted, 2004) ${ }^{2}$, who assessed the influence of sea surface temperatures on the Northern winter stratosphere.

In our current simulations, we have used a similar model setup as in Van Aalst et al. (submitted, 2004b) ${ }^{1}$, with a spectral triangular truncation at T42, which corresponds to a horizontal resolution of about 2.8 by $2.8^{\circ}$ longitude-latitude. Tracer transport is calculated with a flux-form semi-Lagrangian advection (FFSL) scheme (Lin and Rood, 1996); we also performed sensitivity runs with the semi-Lagrangian Transport (SLT) scheme (Rasch and Williamson, 1990; Rasch et al., 1995), which was the standard scheme in ECHAM4, and the Split Implementation of Transport Using Flux Integral Representation (SPITFIRE) advection scheme (Rasch and Lawrence, 1998), which

\footnotetext{
${ }^{2}$ Manzini, E., Giorgetta, M. A., Kornblueh, L., and Roeckner, E.: The influence of sea surface temperatures on the Northern winter stratosphere: Ensemble simulations with the MAECHAM5 model, J. Clim., submitted, 2004.
}

\section{Stratospheric temperatures and transport in a nudged GCM}

M. K. van Aalst et al.

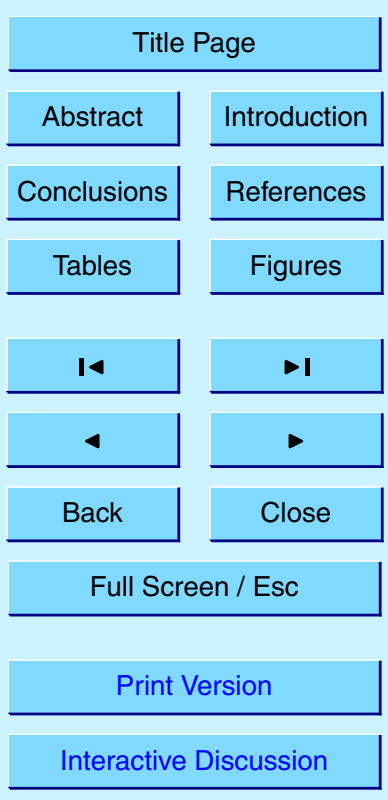


was used in MAECHAM4 by Steil et al. (2003). The time step is $900 \mathrm{~s}$; full radiation calculations are performed every 8 time steps $(2 \mathrm{~h})$.

The nudging setup is similar to the standard runs of Van Aalst et al. (submitted, $2004 \mathrm{~b})^{1}$. Full nudging, with a relaxation time scale of $48 \mathrm{~h}$ for the divergence, $24 \mathrm{~h}$ 5 for temperature and surface pressure, and $6 \mathrm{~h}$ for vorticity (as in Guldberg and Kaas, 2000), is applied between level 7 and level 27 (corresponding to about $223 \mathrm{hPa}$ and about $690 \mathrm{hPa}$ for locations without orography, respectively), with the nudging tapering off exponentially in the three levels above and below (at 50,25 , and $12.5 \%$ of the full strength, respectively). No nudging is applied above level $24(113 \mathrm{hPa})$. To avoid the 10 excitation of spurious gravity waves, the ECMWF data were interpolated to the model grid using a state-of-the-art interpolation scheme, and subsequently filtered by projecting them onto the model normal modes, and filtering out all components faster than $24 \mathrm{~h}$. Even without this slow-normal-mode filtering, our nudging settings have been shown to create minimal artificial forcings in the model (Guldberg and Kaas, 2000). Sea surface temperatures are prescribed consistently from the ECMWF analyses.

In addition to the global nudging in spectral space, our standard simulations also included the MESSy submodel QBO, a nudging of the quasi-biennial oscillation (QBO). The QBO substantially influences the large-scale dynamics and tracer transports in the middle atmosphere (and indirectly also in the troposphere) (Baldwin et al., 2001). Hence, a comparison of our model with the actual atmosphere in a particular period requires a realistic phase of the QBO. However, the low vertical resolution used here because of practical constraints does not allow the direct simulation of the QBO (Giorgetta et al., 2002), so that the QBO is forced externally by assimilation of the observed QBO (as in Giorgetta and Bengtsson, 1999, similar to other GCM experiments with QBO assimilation, such as by Hamilton, 1998). This QBO assimilation consists of a Newtonian relaxation of the zonal wind in the QBO domain towards an idealized QBO that (a) is zonally uniform, (b) has a latitudinal Gaussian bell shape centered on the equator, and (c) evolves in time as observed in wind data from Singapore $\left(1^{\circ} \mathrm{N}, 104^{\circ} \mathrm{E}\right)$ (Naujokat, 1986; Marquardt and Naujokat, 1997). The original observations (up to
ACPD

5, 961-1006, 2005

\section{Stratospheric temperatures and transport in a nudged GCM}

M. K. van Aalst et al.

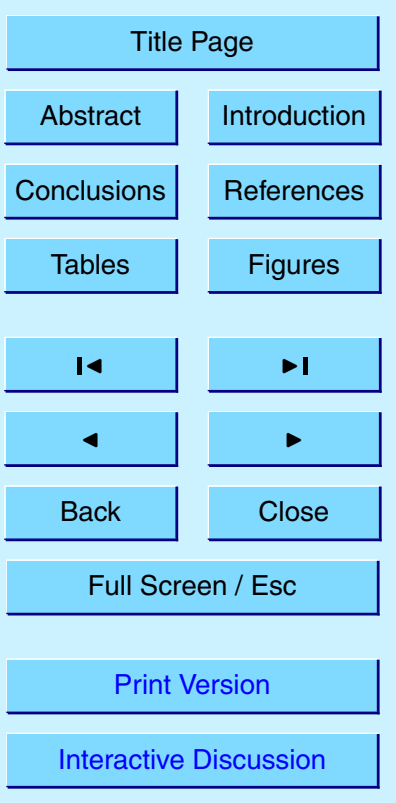


$10 \mathrm{hPa}$ ) were extended to $3 \mathrm{hPa}$ using a backward running propagation operator that exploits the observed regularity in the QBO propagation. This nudging is applied with a relaxation timescale of a week (at the center of the QBO nudging domain, tapering off towards $20^{\circ}$ latitude north and south, and towards the top and bottom of the QBO 5 nudging domain, at 3 and $100 \mathrm{hPa}$ ). This timescale (as in Hamilton, 1998) is sufficient to force the correct QBO phase but leaves the model full freedom to develop its own dynamics on shorter timescales.

The middle atmospheric methane and water vapor fields were updated according to MESSy submodel H2O, in a similar way as Van Aalst et al. (submitted, 2004b) ${ }^{1}$. 10 Methane and water vapor above $100 \mathrm{hPa}$ are initialized using a bimonthly zonal mean climatology prepared from four years (1993-1996) of data from the Halogen Occultation Experiment (HALOE) instrument aboard the Upper Atmosphere Research Satellite (UARS) (see below). Tropospheric methane is set at $1.75 \mathrm{ppmv}$ (distributed over the hemispheres). After initialization, methane is advected as a model tracer, while surface concentrations are kept constant. Methane loss and $\mathrm{H}_{2} \mathrm{O}$ production are simulated by applying monthly zonal mean methane loss fields for reactions with $\mathrm{OH}, \mathrm{Cl}$, and $\mathrm{O}\left({ }^{1} \mathrm{D}\right)$, taken from a chemistry-climate run with MAECHAM4/CHEM (Steil et al., 2003). Photodissociation of methane and water vapor, and reaction of water vapor with $O\left({ }^{1} D\right)$ are not included, which results in a slight high bias of both tracers in the mesosphere. $\mathrm{CO}_{2}$ and tropospheric $\mathrm{N}_{2} \mathrm{O}$ are fixed at 372 ppmv and 320 ppbv, respectively (WMO, 1999). We have used tropopause diagnostics from the MESSy submodel TROPOP, which uses a combination of the WMO tropopause definition (as in Reichler et al., 2003; Dameris et al., 1995) and a dynamic PV criterion $\left(2 \mathrm{~K} \mathrm{~m}^{2} / \mathrm{kg} / \mathrm{s}\right)$.

Our simulations included the period from May 1999 to October 2003, with the first 25 tained essentially four years of model data, including four Arctic and three Antarctic winters, to compare to analyzed temperatures and tracer observations. Besides the base run (with tropospheric and QBO nudging), we performed similar runs without the QBO nudging, and also without the tropospheric nudging. In addition, we performed

ACPD

5, 961-1006, 2005

\section{Stratospheric temperatures and transport in a nudged GCM}

M. K. van Aalst et al.

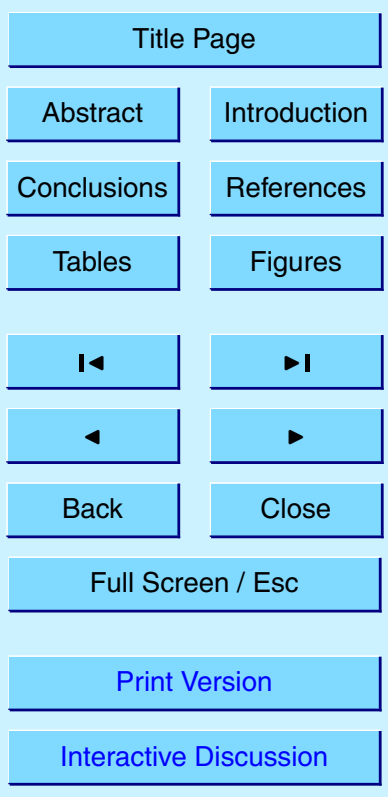

EGU 
shorter (20 months) sensitivity runs with the SLT and SPITFIRE advection schemes, with the FFSL scheme with a surface pressure mass mismatch fixer, and with the FFSL scheme at higher resolution (spectral triangular truncation T63, corresponding to about $1.875 \times 1.875^{\circ}$ latitude-longitude).

\section{3. Analyses and observations}

\subsection{ECMWF data}

Operational analyses from the ECMWF were used as input for the nudging (at altitudes below $113 \mathrm{hPa}$ ) and for comparisons with model temperatures at 70, 50, 30 and $10 \mathrm{hPa}$. Lower stratospheric ECMWF analyses have been shown to agree well with sonde and satellite measurements, particularly also in the polar regions. For instance, Pommereau et al. (2002) and Knudsen et al. (2002) found a minor warm bias of $0.49 \mathrm{~K}$ with a standard deviation of $0.91 \mathrm{~K}$ in comparisons with independent longduration balloon observations for Arctic winter temperatures below $30 \mathrm{hPa}$ in the (relatively cold) winter 1999/2000. Similarly, Hertzog et al. (2004) found a cold bias of about $0.3 \mathrm{~K}$ with a standard deviation of $0.8 \mathrm{~K}$ at $70 \mathrm{hPa}$ in the 2001/2002 Arctic winter, and Knudsen (2003), using data up to $11 \mathrm{hPa}$ from 1999/2000, 2002/2003 and 1996/1997 (ECMWF ERA reanalysis data for the latter) found biases generally well below $1 \mathrm{~K}$, except in the 11-26 hPa layer during the 2002/2003 winter, which showed a cold bias of $1.05 \pm 1.17 \mathrm{~K}$. While Manney et al. (2003) found large differences in PSC coverage between various meteorological analyses, Knudsen (2002) has shown that below 26 $\mathrm{hPa}$, the analyzed temperatures below $\mathrm{T}_{N A T}$ are within $10 \%$ of those observed by radio sondes (i.e. within the error margins). Above $26 \mathrm{hPa}$ however, the ECMWF analyses almost always overestimate the area PSC coverage. At these higher altitudes, the ECMWF temperatures generally become rather uncertain, given the paucity of observations for assimilation.

We note that the quality of the stratospheric ECMWF analyses has generally im-

ACPD

$5,961-1006,2005$

\section{Stratospheric temperatures and transport in a nudged GCM}

M. K. van Aalst et al.

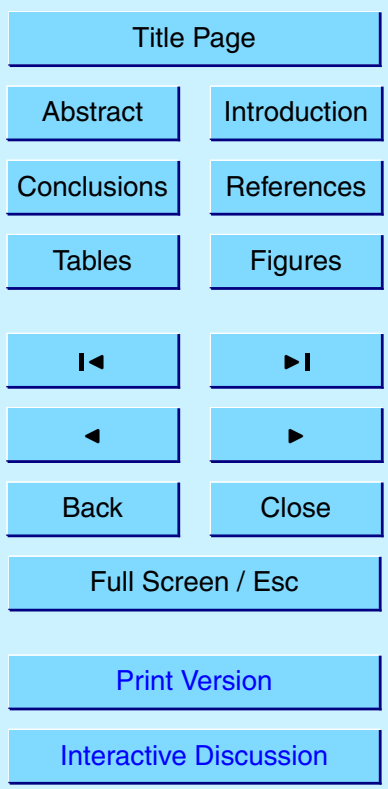

EGU 
proved over time as new model versions have been released and additional satellite observations have been assimilated (Simmons et al., 2005). During the entire 4-year period simulated here, the ECMWF used a model with a top level at $0.1 \mathrm{hPa}$, with 50 vertical levels until 12 October 1999, and 60 levels thereafter. The horizontal reso5 lution was T319 until 21 November 2000 and T511 thereafter, corresponding to grid sizes of about 60 and $40 \mathrm{~km}$, respectively. A slight temperature error may have occurred in the lower stratosphere between October 1999 and 10 April 2000 due to an error in the humidity fields in a shallow layer just above the tropopause in this period (ECMWF website http://www.ecmwf.int, model version history). Shifts in the quality 10 of the analyzed fields could partly be avoided by using reanalysis data, such as from ERA-40 (Simmons and Gibson, 2000), which do suffer from instrument and converge discontinuities, but not from changes in model versions.

\subsection{HALOE observations}

We have used methane and water vapor data from the Halogen Occultation Experi15 ment (HALOE) instrument aboard the Upper Atmosphere Research Satellite (UARS) (Russell et al., 1993). Park et al. (1996) estimated that the total error in methane is within $15 \%$ and the precision is better than $7 \%$ over the 1 to $100 \mathrm{hPa}$ height range. Harries et al. (1996) found that the accuracy of the HALOE $\mathrm{H}_{2} \mathrm{O}$ observations is within $10 \%$ between 0.1 and $100 \mathrm{hPa}$, and within $30 \%$ at the boundaries of its observational 20 range (from the tropopause to about $0.002 \mathrm{hPa}$ ). In the lower stratosphere, the precision is a few percent. For both methane and water vapor the vertical resolution is about $2 \mathrm{~km}$. In this study, we have used the version 19 data (available at the HALOE website http://haloedata.larc.nasa.gov), which should have an improved accuracy compared to the version 17 products used in the validation papers, particularly in the lower parts of 25 the observational range.

The HALOE data are used in two ways. As noted above, the MESSy submodel $\mathrm{H} 2 \mathrm{O}$ initializes our water vapor and methane fields (above $100 \mathrm{hPa}$ ) with a climatology of HALOE data (compiled in 1993-1996). Secondly, we have used HALOE mea-
ACPD

5, 961-1006, 2005

\section{Stratospheric temperatures and transport in a nudged GCM}

M. K. van Aalst et al.

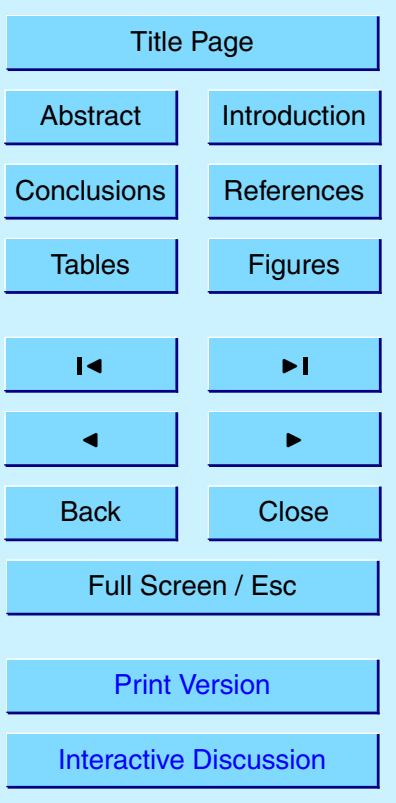

EGU 
surements from the period that was simulated in our experiments to test the model representation of tracer transports.

\section{Results: temperatures}

\subsection{Antarctic and Arctic}

5 Figure 1 shows a comparison of temperatures from MAECHAM5/MESSy with those from ECMWF analyses, at $80^{\circ} \mathrm{S}, 10$ and $70 \mathrm{hPa}$. Similar analyses were examined for 30 and $50 \mathrm{hPa}$ (as discussed below), for the pole region and $70^{\circ}$ latitude (with very similar results as at $80^{\circ}$ ). For each month, we collected the temperatures at all grid points along the latitude band (using 12-hourly data, for both ECMWF and 10 MAECHAM5/MESSy). The figure shows the monthly median and mean temperatures, as well as the 33 and 66 percentiles and the minimum and maximum temperatures, thus providing an impression of the distribution and variability of both our model and the higher resolution analyses.

The figure shows that the model accurately captures the interannual variability, especially of the lowest temperatures reached in the Antarctic vortex, including the cold winter minimum of 2003. During each winter, the model captures the temperature development, as well as the variability in the monthly datasets (minima and maxima as well as standard deviations or 33/66 percentiles).

This is confirmed by Fig. 2, which shows the fractional area south of $50^{\circ} \mathrm{S}$ with temperatures lower than $190 \mathrm{~K}$ (integral calculated for each month, based on 12-hourly data), at 89,70 and $54 \mathrm{hPa}$, as an indication of the model's ability to simulate the extent of very low temperatures required for the formation of PSCs, which promote chlorine activation and ozone destruction. At $89 \mathrm{hPa}, \mathrm{MAECHAM} 5 / \mathrm{MESSy}$ has a small cold bias, but at 54 and $70 \mathrm{hPa}$ (the altitude of largest ozone loss), the model performs relatively well. Table 1 shows the relative difference between MA-ECHAM5 and ECMWF in area with temperatures lower than $190 \mathrm{~K}$ during the month of August, the coldest
ACPD

5, 961-1006, 2005

Stratospheric temperatures and transport in a nudged GCM

M. K. van Aalst et al.

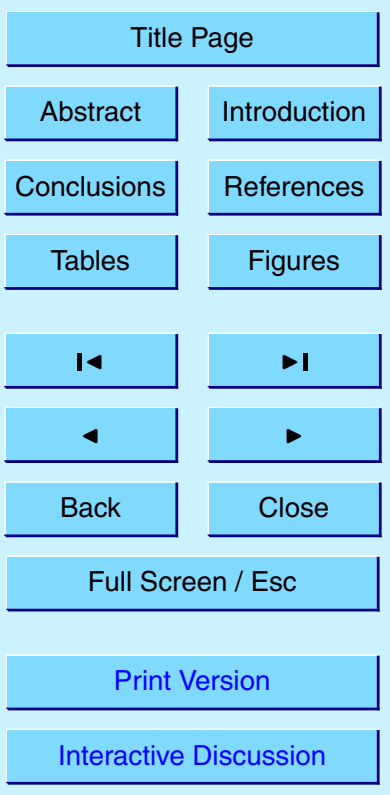


month. MAECHAM5/MESSy tends to overestimate the area colder than $190 \mathrm{~K}$ at 54 and $70 \mathrm{hPa}$ by about $10 \%$, except in 2001 , where it simulates a substantially larger cold area than the ECMWF analysis. The model reproduces the relatively warm 2002 winter quite well.

5 Relatively larger differences between MAECHAM5/MESSy and the ECMWF analyses occur at the end of the Southern winter, particularly in the area between 50 and $70 \mathrm{hPa}$. The mean temperature in MAECHAM5/MESSy increases more rapidly than in the ECMWF analyses, and the area with temperatures below $190 \mathrm{~K}$ decreases too rapidly, except in late winter 2002 . This relative warming can be explained by the use of 10 the Fortuin and Kelder (1998) ozone climatology, which is representative for conditions in the late 1980s, when the ozone hole was much smaller. When sunlight returns to the pole, the climatology's overestimate of ozone concentrations results in too much absorption of solar radiation and accelerated warming. This explanation complies with the better model performance for 2002, after an unusually disturbed winter with a re15 latively weak ozone hole after the vortex breakup in September. Note that this rapid warming tendency is expected to vanish in simulations with coupled chemistry, which will generate more realistic ozone concentrations in the Antarctic vortex. Indeed, Steil et al. (2003) found that simulations with coupled chemistry generally simulated a shift to lower average temperatures at the South Pole ranging from $5-10 \mathrm{~K}$ in October to

$10-14 \mathrm{~K}$ in November. GCM simulations without coupled chemistry should thus use an updated ozone climatology, or adding a simplified ozone loss parameterization within the polar vortex.

Larger discrepancies between MAECHAM5/MESSy and the ECMWF analyses appear in summer temperatures, where MAECHAM5/MESSy consistently shows a cold bias of a few degrees. This pattern is strongest at 70 and $50 \mathrm{hPa}$, weaker at $30 \mathrm{hPa}$, and virtually absent at $10 \mathrm{hPa}$. We assume that it is similar (though smaller) to the general cold bias in the lower stratosphere, as simulated by most middle atmosphere GCMs (Pawson et al., 2000). However, since stratospheric temperature gradients are relatively weak in summer, we expect that the effect on stratospheric dynamics and
ACPD

5, 961-1006, 2005

\section{Stratospheric temperatures and transport in a nudged GCM}

M. K. van Aalst et al.

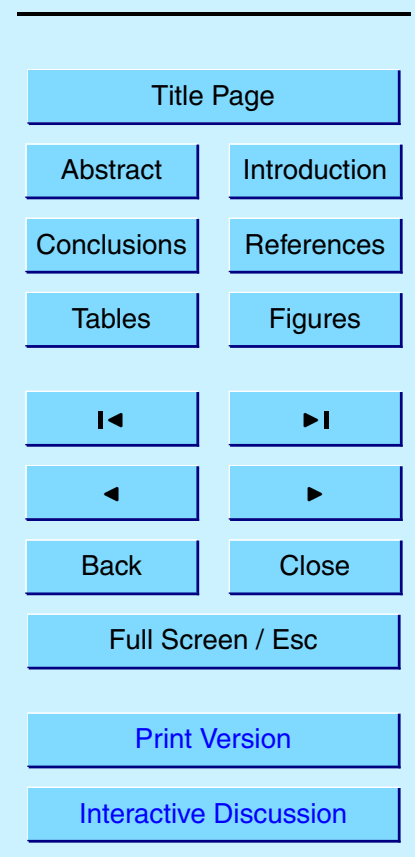

EGU 
tracer transports is relatively small.

Figure 3 shows monthly temperatures for $80^{\circ} \mathrm{N}$. During Arctic summer, the model exhibits a similarly small cold bias as in the Southern Hemisphere, but in this case, it also appears at $10 \mathrm{hPa}$. In winter, the interannual variability is much larger in both

5 MAECHAM5/MESSy and ECMWF, and the match between the two is slightly worse than for the Antarctic, reflecting the more dynamic stratosphere and planetary wave driving (contrary to the Antarctic, where radiative cooling and gravity wave forcing dominate during most of the winter). In some instances this can result in monthly mean temperature differences up to $15 \mathrm{~K}$ (at $10 \mathrm{hPa}$ in 1999/2000), and typically of the order 10 of $\pm 5^{\circ}$, without a clear bias in any direction.

The main discrepancies are related to differences in the timing of sudden Arctic stratospheric warmings. For instance, the evolution of temperatures in 1999/2000 at $70 \mathrm{hPa}$ is captured quite well. In the upper stratosphere, however, MAECHAM5/MESSy shows a strong major warming in early March 2000, after which the vortex does not 15 fully recover (Fig. 4). The ECMWF analyses indeed show a warming about 10 days later, but subsequently the vortex recovers, particularly in the lower stratosphere. Figure 5 shows that a similar $\sim 5$ day advance of the warming occurs for December 2001, being a major event as discussed by Naujokat et al. (2002). In some other cases however, the model captures the evolution of Arctic temperatures very well. For instance,

in 2000/2001 the model exhibits a comparably disturbed vortex as in the analyses after late January, and then shows an analogous recovery around 20 February, with persistent cold temperatures well into March and April. Similarly good simulations are obtained in the Southern Hemisphere, for instance for September 2002, which includes the unique 2002 Antarctic vortex split (shown in Fig. 6).

25 The model thus has a mixed degree of success in capturing specific Arctic sudden stratospheric warmings, especially their timing, reflecting the fact that such events are driven by tropospheric waves as well as internal middle atmospheric dynamics (and their mutual interaction). In any case, the nudging clearly helps generating many characteristics of the overall temperature evolution during Arctic stratospheric winters.
ACPD

5, 961-1006, 2005

\section{Stratospheric temperatures and transport in a nudged GCM}

M. K. van Aalst et al.

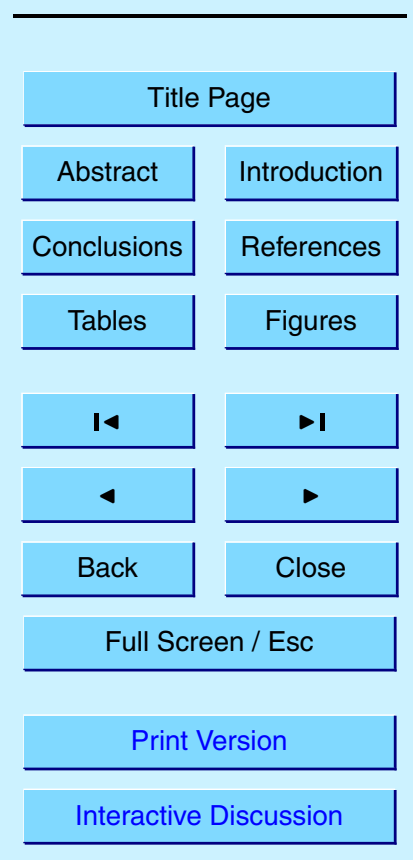

EGU 
Figure 7 present the same results as in the bottom panels of Figs. 1 and 3, but now from a run without tropospheric nudging (except in the first four months). Note that this run did include the observed sea surface temperatures, as well as the equatorial QBO nudging. A comparison with Figs. 1 and 3 clearly shows that in both hemispheres, 5 the nudged run provides a much closer match to the observed evolution of the stratospheric winters, even though in the Arctic the timing of specific stratospheric warmings is not simulated very well.

\subsection{Midlatitudes}

At midlatitudes $\left(60,50\right.$ and $40^{\circ}$ north and south), the mean annual cycle as well as the seasonal and interannual variability in monthly mean temperatures are very well captured. At 70,50 , and $30 \mathrm{hPa}$, the model exhibits a small summer cold bias (up to about $2 \mathrm{~K}$ ) similar to that at the poles. At $10 \mathrm{hPa}$ however, the model shows a significant winter warm bias of several degrees $\mathrm{K}$ relative to the ECMWF analyses, particularly in the Southern Hemisphere. As an example, Fig. 8 shows the temperatures at $50^{\circ} \mathrm{S}$ at 10 and $70 \mathrm{hPa}$.

\subsection{Subtropics and tropics}

We found that in the northern subtropical lower stratosphere $\left(20^{\circ} \mathrm{N}, 70 \mathrm{hPa}\right.$ and $\left.50 \mathrm{hPa}\right)$ the annual cycle in temperature of MAECHAM5/MESSy is smaller than of ECMWF; our model shows no or only a small cold bias in summer, but a substantial one in winter, up to about $5^{\circ}$. This seasonal temperature bias is restricted to the outer reaches of the domain of the QBO nudging (which tapers off between 10 and $20^{\circ}$ North and South), and does not occur in a run without QBO nudging. It is caused by the uniform zonal winds used by the QBO nudging domain, which do not include the annual cycle in zonal wind at the subtropics. Sensitivity runs with more limited QBO nudging domains suggest that in future simulations the QBO nudging should be limited to to a somewhat smaller latitude band around the equator (e.g. up to $15^{\circ}$ North and South).
ACPD

5, 961-1006, 2005

Stratospheric

temperatures and

transport in a nudged GCM

M. K. van Aalst et al.

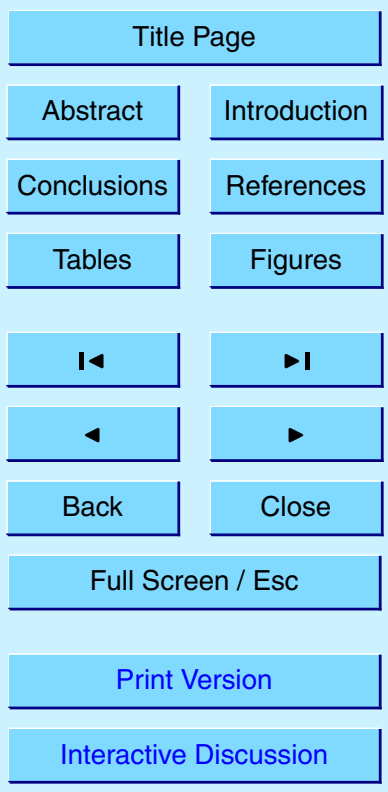


At all locations apart from the subtropics (discussed above), the fit between MAECHAM5/MESSy and ECMWF is improved for the run with QBO nudging. Not only, as expected, at the equator (where the QBO nudging is strongest), but also at midlatitudes and at the poles (although the effects there are smaller). A comparison 5 between equatorial temperatures at $10 \mathrm{hPa}$ for the runs with and without QBO nudging (Fig. 9) indicates that the QBO forcing substantially improves the results; the run without QBO nudging clearly shows a bias that varies in parallel with the QBO cycle. Note also that the temporal tendency of the interannual variability is generally well captured, however, our model is often a few degrees colder than indicated by the ECMWF analy10 ses. At $70 \mathrm{hPa}$, it is highest in the northern summer and very small in winter; at higher altitudes, it is more constant through the seasons.

\section{Results: methane and water vapor}

We have also evaluated stratospheric methane and water vapor distributions (from the MESSy submodel $\mathrm{H} 2 \mathrm{O}$ ) to assess tracer transport throughout our four-year simula15 tions. Unfortunately, there is no equivalent (in terms of coverage and resolution) of the ECMWF analyzed temperatures for long-lived tracers, so we had to rely on less comprehensive comparison methods. Firstly, we have compared "snapshots" of HALOE observations, both on individual days and during one HALOE sweep (which provides a zonal mean latitude-altitude perspective). Secondly, we have compared the time evo20 lution of modeled methane and water vapor concentrations at particular altitudes and latitudes with HALOE measurements taken around those locations.

\subsection{Arctic and Antarctic methane}

As in the simulations of Van Aalst et al. (submitted, 2004b) ${ }^{1}$, we obtained an excellent representation of the major warming and the split vortex in September 2002. Later in

Antarctic winters, the model also captures specific details of the vortex evolution. As
ACPD

5, 961-1006, 2005

\section{Stratospheric temperatures and transport in a nudged GCM}

M. K. van Aalst et al.

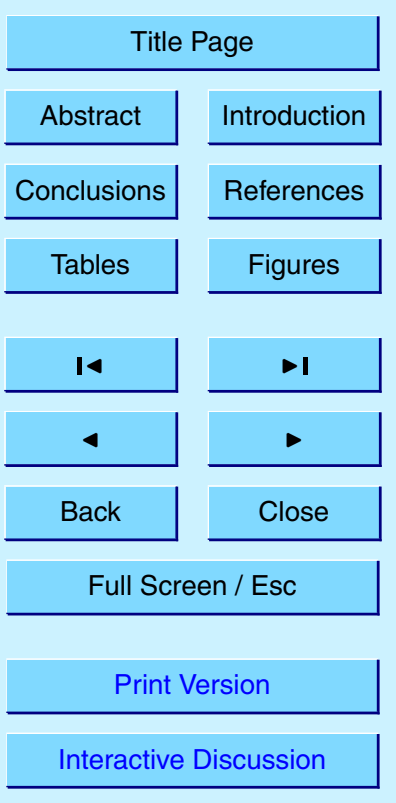

EGU 
an example, Fig. 10 shows methane concentrations at $74^{\circ} \mathrm{S}$ on 3 November 2000 in our MAECHAM5/MESSy simulations and as observed by HALOE (the HALOE image is composed of 15 vertical profiles observed over the course of the day). The model clearly reproduces the location of the vortex, and the edges of the vortex are suffi5 ciently sharp. Within the vortex, however, the model generally overestimates methane concentrations below about $30 \mathrm{hPa}$. The tropopause transport barrier seems too be too high, and the vertical gradient too weak. It should be noted, however, that the accuracy of the HALOE data around the tropopause is relatively low. In the midlatitudes (roughly between 120 and $360^{\circ}$ ) the simulated concentrations in the upper stratosphere 10 are quite realistic; in the lower stratosphere however, the vertical gradients seem too weak, resulting in an underestimate of methane between about 20 and $5-10 \mathrm{hPa}$, and an overestimate from the tropopause to about $50 \mathrm{hPa}$.

We obtained similar results for the Northern Hemisphere, to the extent that the comparisons are unaffected by the different occurrence of stratospheric warmings, as dis15 cussed above. For instance, for the 1999/2000 winter, the evolution of the late winter vortex was quite different than in reality, so that a comparison with features in March would be meaningless. A slightly earlier comparison with the HALOE profiles on 20 February however (Fig. 11), shows that the model does simulate the vortex edge at around $300^{\circ}$ longitude. As in the Southern Hemisphere however, the methane concentrations in the modeled vortex fragment below about $40 \mathrm{hPa}$ are not sufficiently low. In addition, contrary to the observations, the model also simulates a second feature in the upper stratosphere (at about $50^{\circ}$ longitude).

The transport deficiencies in the lower polar stratosphere are also illustrated by our longitudinal model-HALOE comparisons at $70^{\circ} \mathrm{N}$, shown in Fig. 12 (with decreasing mixing ratios on the vertical axis, so that the lines are represented in the order of their altitude. This figure shows monthly and zonal mean model data (solid lines), and daily mean HALOE data (marks) from all days in our four-year run when the mean latitude of the HALOE observations were within a $3^{\circ}$ window around $70^{\circ} \mathrm{N}$ (if more than one daily mean latitude during one pass fell in the range, we took the one closest to the
ACPD

5, 961-1006, 2005

\section{Stratospheric temperatures and transport in a nudged GCM}

M. K. van Aalst et al.

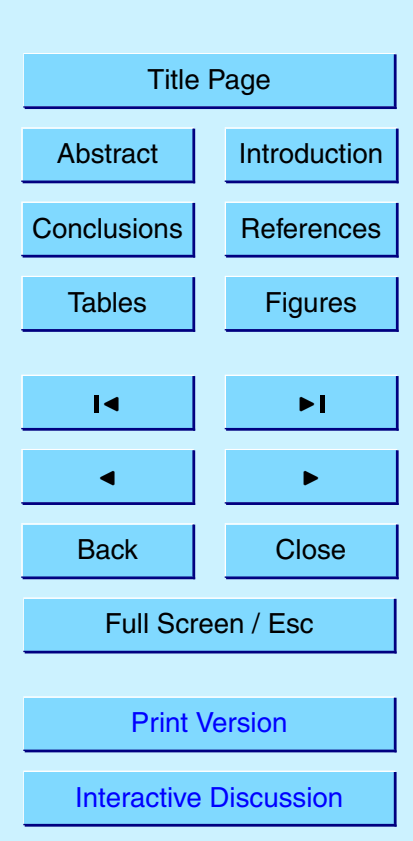


target latitude). Note that this method introduces two comparison problems. Firstly, MAECHAM5/MESSy profiles are consistently collected at a single latitude whereas the average latitude of the HALOE profiles varies. Furthermore, the HALOE data for a particular day do not originate in that average latitude, but are collected at different 5 times and at slightly different latitudes (the range on one day can be up to about $8^{\circ}$ halfway the latitude sweep at lower latitudes, less towards the turnaround points at higher latitudes). The variability induced by this sampling method is often too high to be able to assess the model's ability to generate interannual variability in tracer transport. Finally, towards the poles, the coverage of the HALOE measurements diminishes, 10 particularly during polar winters.

At $70^{\circ} \mathrm{N}$, the model reproduces the rise in lower stratospheric concentrations when the polar vortex disintegrates in spring (after light returns - when HALOE can perform measurements). The quantitative match of the methane concentrations is very good at $10 \mathrm{hPa}$ (and higher), but rather poor in the lower stratosphere, consistent with the results of the snapshots at 3 November and 20 February 2000 (Figs. 10 and 11). The reason is a too high tropopause and a too weak vertical gradient up to about $40 \mathrm{hPa}$.

This lack of isolation of the lower vortex also results in an underestimate of descent rates in the vortex (as estimated on the basis of tracer concentrations through the winter). Van Aalst et al. (2004a) identified a similar lack of descent in the lower part of 20 the Arctic vortex in fully nudged simulations of the 1999/2000 winter (with MAECHAM4 and the semi-Lagrangian advection scheme). We repeated the tracer descent calculations from that analysis with our current model data, and found very similar results: a good match with observations (Greenblatt et al., 2002) of descent starting at potential temperatures around 550 and $500 \mathrm{~K}$ (about $30-40 \mathrm{hPa}$ ) in early December, but an underestimate of descent starting around 450 and $400 \mathrm{~K}$ (about $50-100 \mathrm{hPa}$ ). This problem may substantially affect both transport and chemistry in the lower polar vortex, and requires careful attention in the analysis of model data from that region.

In the Antarctic, HALOE observations regularly capture vortex features during October, November and December when the orbit crosses $70^{\circ}$ south. Given the large

ACPD

5, 961-1006, 2005

\section{Stratospheric temperatures and transport in a nudged GCM}

M. K. van Aalst et al.

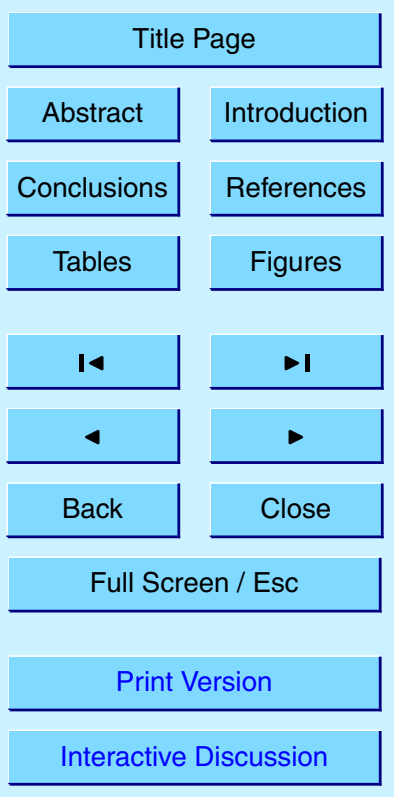

EGU 
differences in concentration inside and outside the vortex, this introduces too much variability to make a useful comparison like the one in Fig. 12 at $70^{\circ} \mathrm{N}$ (in this case, the only meaningful comparison between MAECHAM5/MESSy and HALOE is to take individual days and latitudes, as in the snapshots discussed above). Nevertheless, the 5 overall impression of such comparisons is the same as in the Northern Hemisphere: too high methane values in the lowermost stratosphere, and suppressed descent, apparently due to too strong vertical mixing.

\subsection{Global methane}

The equatorial region, where trace gases like methane enter the stratosphere and are 10 transported upwards, plays a crucial role in middle atmospheric transport.

Figure 13 shows a comparison between modeled monthly mean $\mathrm{CH}_{4}$ data and HALOE observations at the equator. After substantial differences in the first few months (caused by the initialization, which was based upon 3 years of HALOE data for April/May, not specifically for 1 May 1999), the match is generally very good. The model also captures the modulation of the methane concentrations by the QBO, although it is slightly weaker than in the HALOE measurements (for instance at $10 \mathrm{hPa}$ ). As expected, the run without QBO nudging did not show this modulation, resulting in a substantially poorer match with the HALOE measurements (here, and in other parts of the stratosphere).

20 Figure 14 shows a comparison of modeled zonal mean methane concentrations on 23 August 2000, compared to observations from 40-day HALOE sweeps around that day. It shows a general agreement in concentrations, as well as a good reproduction of the instantaneous shape of the concentration profiles (similar model-HALOE agreement is obtained at other days throughout the run). However, methane concentrations

in the lower stratosphere at southern midlatitudes are too high, and the vertical gradient at the top of the "shoulder" is too weak. These problems also appear in detailed comparisons. In northern midlatitudes and in the subtropics, the HALOE measurements are generally in good agreement with the model's monthly mean methane concentra-
ACPD

5, 961-1006, 2005

\section{Stratospheric temperatures and transport in a nudged GCM}

M. K. van Aalst et al.

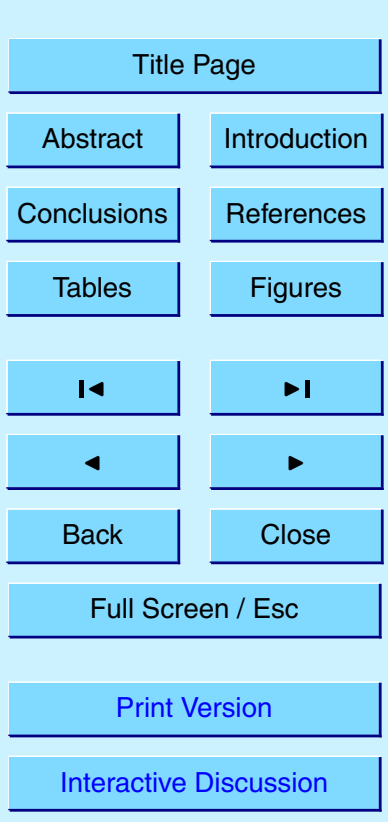

EGU 
tions, and some, but not all specific features of the interannual variability are captured by the model (e.g. Fig. 15). At southern midlatitudes however, the vertical gradient is too smooth, and the model does not capture the annual shifts in methane concentrations in the mid-stratosphere (again, because the weak gradients at the top of the 5 midlatitude shoulder).

\subsection{Water vapor}

Given the realistic methane concentrations in most of the stratosphere, the model also simulates an accurate chemical source for water vapor. However, middle atmospheric water vapor concentrations also depend on the seasonal water vapor cycle in the air that enters the stratosphere. The general pattern of the upward propagation of this seasonal cycle, the tropical tape recorder (Mote et al., 1996), is well modeled, as shown in Fig. 16.

The model also generates realistic stratospheric water vapor distributions, although it fails to capture several important details in the lower stratosphere. This can be seen in 15 Fig. 17, which shows the same model-HALOE comparisons as in Fig. 14 (zonal mean, latitude-altitude) and Fig. 10 (longitude-altitude), but now for water vapor. The model does not simulate the lowest concentrations in the lower equatorial stratosphere, and falls short with respect to the minimum of the previous year around $24 \mathrm{hPa}$, clearly visible in HALOE data. In midlatitudes, the vertical gradient above the water vapor 20 minimum in the lower stratosphere is too weak, while concentrations in the lowermost stratosphere too high. At the poles, a similar transport problem appears as in methane, with substantially too high water vapor in the lowermost stratosphere. On 3 November 2000 , the overall shape of the vortex feature and the location of minima and maxima are well modeled, but the model simulates a too high tropopause and fails to capture 25 the deepest minima in the lower stratosphere. In midlatitude air, the same smoothed vertical gradient appears as in methane.
ACPD

5, 961-1006, 2005

\section{Stratospheric temperatures and transport in a nudged GCM}

M. K. van Aalst et al.

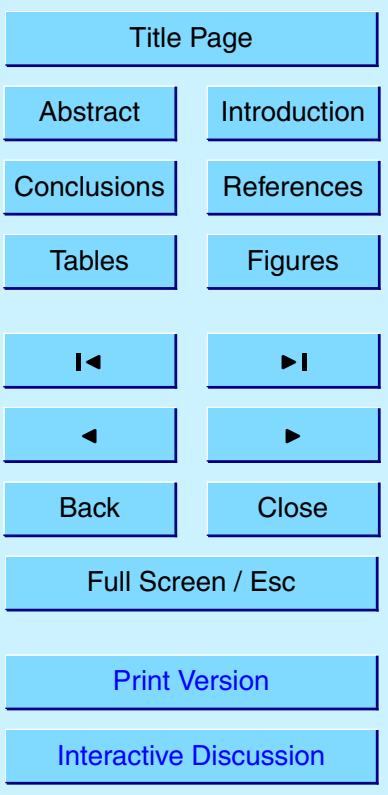




\section{Discussion}

We found that MAECHAM5/MESSy with nudging up to $113 \mathrm{hPa}$ simulates the main features of the large-scale circulation in the middle atmosphere, including its seasonal and interannual variability. However, specific aspects of polar winters, particularly the 5 timing of sudden stratospheric warmings in the Northern Hemisphere, are not always accurately reproduced. This mainly reflects the more dynamically active circumstances in the Northern Hemisphere, and may partly be related to the model's relatively coarse vertical resolution, which is known to be insufficient to reproduce certain aspects of wave-driven dynamics (including the QBO).

10 MAECHAM5/MESSy generally simulates realistic temperatures, including the temperature minima in the Antarctic winter. A few biases remain, including a cold bias throughout the lower stratosphere (consistent with, e.g. the model intercomparison by Pawson et al., 2000). Sensitivity runs without tropospheric nudging (but with correct sea surface temperatures and the QBO forcing) showed that the tropospheric nudging 15 is not for the cause of these biases in the model, and it does not create other ones. This finding confirms that our nudging settings and normal mode filtering prevent the nudging from generating spurious gravity waves that might affect middle atmospheric dynamics.

The tracer distributions are generally realistic except for too weak gradients at mid20 latitudes, and, particularly, a too high tropopause and too weak vertical gradient in the polar lower stratosphere, which also results in an underestimate of descent rates in the polar vortex. Similar problems with tracer descent in the vortex were identified in CTM studies (though not affected by a tropopause bias). For instance, Plumb et al. (2002) identified excessive horizontal mixing inside the vortex and between vortex and extra-vortex air in CTM studies for the 1999/2000 winter. In an analysis that separated horizontal and vertical tracer exchange, Considine et al. (2003) found that their CTM exhibited compensating errors; too vigorous descent in the meteorological input data was counterbalanced by an overestimate of horizontal mixing. Using the
ACPD

5, 961-1006, 2005

\section{Stratospheric temperatures and transport in a nudged GCM}

M. K. van Aalst et al.

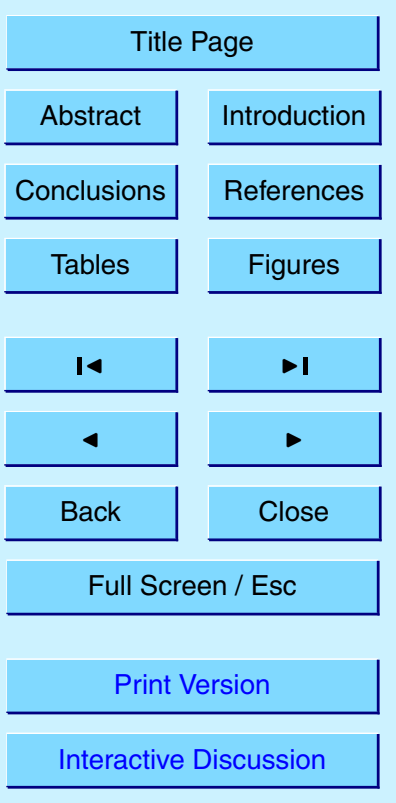


TM5 zoom model, Bregman (personal communication) show that the problems with tracer descent in the 1999/2000 Arctic vortex that were identified by Van den Broek et al. (2003) were partly related to the reduced grid employed in earlier versions of that CTM (a problem that does not apply to MAECHAM5/MESSy). However, they also 5 showed that substantial improvements were achieved with the second order advection scheme developed by Prather (1986) than with the more diffuse Slopes advection scheme (Russell and Lerner, 1981), and that a similar improvement resulted from a substantially higher horizontal resolution $\left(1 \times 1\right.$ instead of $\left.2 \times 3^{\circ}\right)$. Unfortunately, both solutions (either the second order advection or the higher resolution) come at a high 10 price in terms of computing resources.

In our simulations, we also obtained a slight improvement in runs at higher horizontal resolution (T63 instead of T42). If horizontal mixing would be the primary cause of the relatively high methane concentrations in the lower vortex, however, we would also expect a more diffusive tracer advection scheme to perform worse than the current 15 FFSL scheme, which did not appear to be the case. Instead, sensitivity tests with the more diffuse semi-Lagrangian transport scheme produced better results in the lower vortex, although the best results were achieved with the SPITFIRE advection scheme, which is least diffusive of the three. We note however, that the SPITFIRE scheme underestimates upward transport at the equator (as noted by Steil et al., 2003) while the semi-Lagrangian scheme does not capture sharp gradients, for instance at the subtropical barrier and at edge of the vortex, so that all three schemes have significant drawbacks. In addition, even the (least diffusive) SPITFIRE scheme still overestimates methane in the lower stratospheric polar vortex. We suspect that the vertical resolution may be an important factor, not the least because a higher vertical resolution would 25 likely also result in a lower tropopause (as in the runs by Roeckner et al. (2004) with the standard ECHAM5 up to $10 \mathrm{hPa}$ ). Therefore, it would be interesting to repeat the simulations with the MAECHAM5 version with higher vertical resolution employed by Giorgetta et al. (2002), which reproduces a QBO without assimilation (although a weak nudging might still be needed to keep the model's internal QBO synchronized with the
ACPD

5, 961-1006, 2005

\section{Stratospheric temperatures and transport in a nudged GCM}

M. K. van Aalst et al.

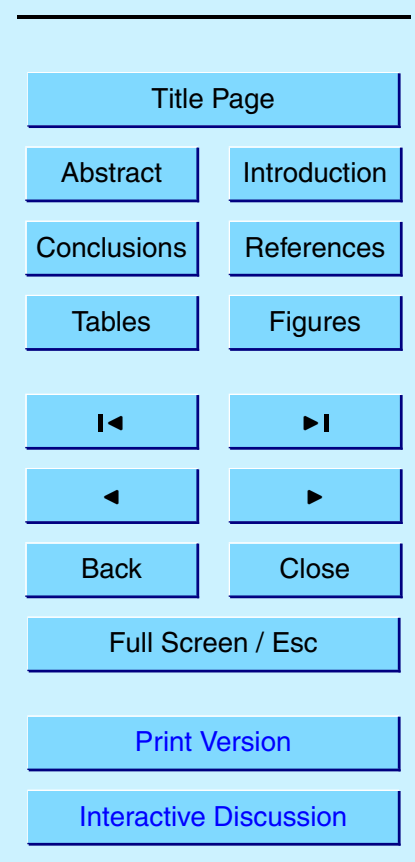

EGU 
observations), and should also perform better in simulating wave phenomena in polar winters. Bregman (personal communication) found that in runs with the TM5 CTM at very high resolution (up to one by one degree), the vertical resolution did not have much influence on tracer transport below $10 \mathrm{hPa}$. We emphasize however, that regardless of 5 the model resolution, CTM winds are taken from the high-resolution ECMWF analyses. In the case of our MAECHAM5/MESSy runs, the vertical resolution also affects the model dynamics, including the location of the tropopause.

Finally, we note that the advection in MAECHAM5/MESSy suffers from a mass imbalance, caused by a mismatch between the mass fluxes and surface pressure tendencies 10 (which are calculated independently), and the transformation of spectral divergence, vorticity and surface pressure to three-dimensional winds for trace gas advection at the Gaussian grid (see Jöckel et al., 2001; Bregman et al., 2003). Sensitivity tests with an iterative correction of this mismatch showed that this is not the primary cause of the transport problems in the polar lower stratosphere (although it did create significant changes at some other locations in the stratosphere). Ideally, GCMs should provide a consistent representation of dynamics and transport on one grid. Yet another way to improve stratospheric transport would be to employ an isentropic vertical coordinate system (Mahowald et al., 2002), but this would require equally dramatic model changes, unsuited for coupled stratosphere-troposphere simulations.

\section{Conclusions}

We have performed a multi-year integration with the MAECHAM5/MESSy middle atmosphere GCM, while nudging the dynamics in the free troposphere (below $113 \mathrm{hPa}$ ) towards ECMWF meteorological analyses. In addition, we force a realistic QBO by assimilation of equatorial zonal wind observations. We show that this model setup allows simulations of many synoptic features of the middle atmospheric dynamics. In Antarctic winters, the model generally reproduces the observed stratospheric meteorology very closely. In the Arctic region, however, the model does not always capture the
ACPD

5, 961-1006, 2005

\section{Stratospheric temperatures and transport in a nudged GCM}

M. K. van Aalst et al.

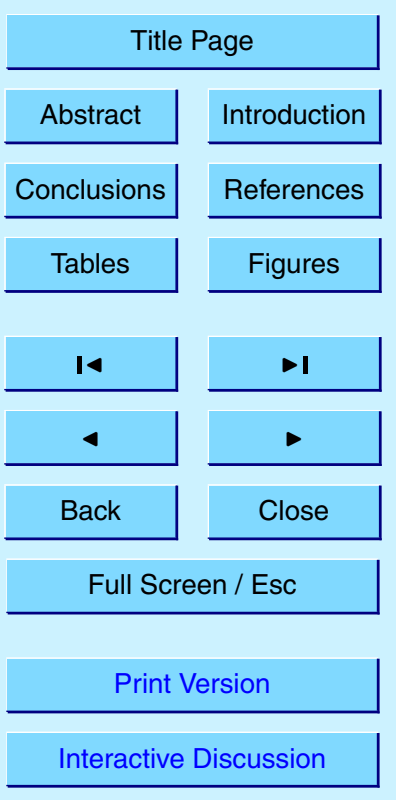

EGU 
timing and evolution of sudden stratospheric warmings, reflecting the more dynamic stratosphere in Northern compared to Southern winters. We conclude that this setup provides good opportunities for further studies with coupled-climate simulations of the middle atmosphere, for instance for the period covered by the ERA-40 reanalysis, but 5 that comparisons with measurements on individual days in the Arctic must be interpreted with care.

Comparing the modeled temperatures to those in the ECMWF analyses, we found that the model exhibits a slight cold bias in the lower stratosphere, particularly at midlatitudes, and at the poles during summer. Arctic and Antarctic winter temperatures are 10 simulated very well, including the extent of low temperatures needed for the formation of PSCs. A warm bias in polar spring will likely be reduced in simulations with coupled chemistry instead of the current ozone climatology.

Stratospheric methane and water vapor concentrations generally compare well to HALOE observations, except in the equatorial lower stratosphere, where the water vapor minimum is not well simulated, and in the polar lower stratosphere, where the model simulates a too high tropopause and too weak vertical gradients. The latter transport problem may provide limitations for coupled chemistry-climate studies of polar ozone loss. The choice of the advection scheme and the horizontal resolution both play a role, but the problem will probably be reduced most effectively by enhancing the vertical resolution. Such a higher resolution could also produce an explicit QBO (i.e. without QBO nudging) and might improve the simulation of dynamic tropospherestratosphere coupling in the Arctic region.

At the current vertical resolution, we find that the assimilation of observed stratospheric equatorial zonal winds to force a realistic QBO improves our results: it not only results in a better match of equatorial winds and temperatures with the ECMWF analyses, but also helps to simulate QBO-like features in the global tracer fields, and improves the temperature fields at the poles. However, the extent of the QBO nudging domain should be chosen carefully to avoid suppression of the subtropical annual cycle in winds and temperatures.

\section{ACPD}

5, 961-1006, 2005

\section{Stratospheric temperatures and transport in a nudged GCM}

M. K. van Aalst et al.

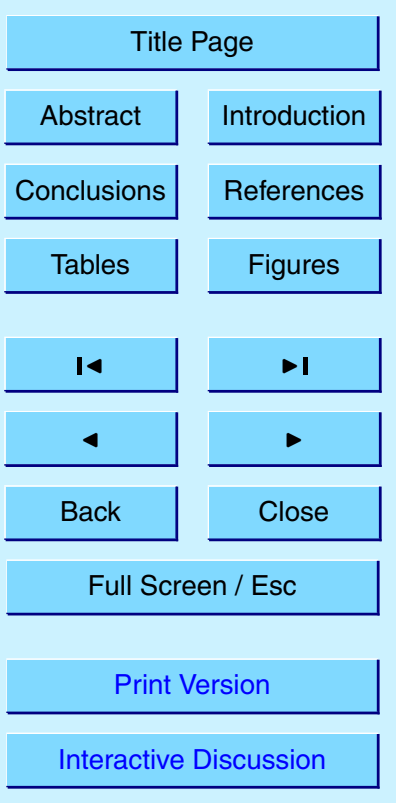


Acknowledgements. We thank the HALOE team at NASA/Langley for making their data available on the internet. The computer simulations were performed at the Computing Centre of the Max Planck Society in Garching (RZG), and at the Dutch computing center SARA (with support from the Netherlands Computing Facilities Foundation NCF).

\section{References}

Austin, J.: A three-dimensional coupled chemistry-climate model simulation of past stratospheric trends, J. Atmos. Sci., 59, 218-232, 2002.

Austin, J., Shepherd, T. G., Schnadt, C., Rozanov, E., Pitari, G., Pawson, S., Newman, P., Nagashima, T., Manzini, E., Dameris, M., Brühl, C., and Beagley, S. R.: Uncertainties and assessments of chemistry-climate models of the stratosphere, Atmos. Chem. Phys., 3, 1-27, 2003,

SRef-ID: 1680-7324/acp/2003-3-1.

Baldwin, M. P., Gray, L. J., Dunkerton, T. J., Hamilton, K., Haynes, P. H., Randel, W. J., Holton, J. R., Alexander, M. J., Hirota, I., Horinouchi, T., Jones, D. B. A., Kinnersley, J. S., Marquardt, C., Sato, K., and Takahashi, M.: The quasi-biennial oscillation, Rev. Geophys., 39, 179-229, 2001.

Bregman, A., Segers, A., Krol, M., Meijer, E., and van Velthoven, P.: On the use of massconserving wind fields in chemistry-transport models, Atmos. Chem. Phys., 3, 447-457, 2003,

20 SRef-ID: 1680-7324/acp/2003-3-447.

Considine, D. B., Kawa, S. R., Schoeberl, M. R., and Douglass, A. R.: $\mathrm{N}_{2} \mathrm{O}$ and $\mathrm{NO}_{\mathrm{y}}$ observations in the 1999/2000 Arctic Polar Vortex: Implications for transport processes in a CTM, J. Geophys. Res., 108(D5), 4170, doi:10.1029/2002JD002525, 2003.

Fortuin, J. P. F. and Kelder, H.: An ozone climatology based on ozonesonde and satellite measurements, J. Geophys. Res., 103(D24), 31 709-31734, 1998.

Fritts, D. C. and Alexander, M. J.: Gravity wave dynamics and effects in the middle atmosphere, Rev. Geophys., 41(1), art. no. 1003, doi:10.1029/2001RG000106, 2003.

Giorgetta, M. A. and Bengtsson, L.: The potential role of the quasi-biennial oscillation in the stratosphere-troposphere exchange as found in water vapour in general circulation model experiments, J. Geophys. Res., 104, 6003-6019, 1999.

ACPD

$5,961-1006,2005$

\section{Stratospheric temperatures and transport in a nudged GCM}

M. K. van Aalst et al.

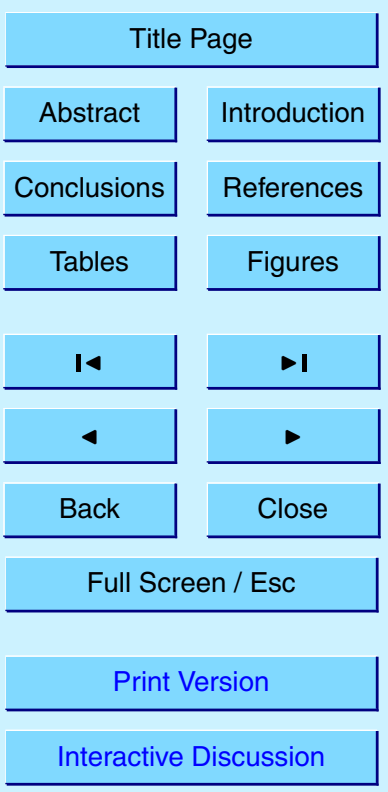

EGU 
Giorgetta, M. A., Manzini, E., and Roeckner, E.: Forcing of the quasi-biennial oscillation from a broad spectrum of atmospheric waves, Geophys. Res. Lett., 29(D8), 1245, doi:10.1029/2002GL014756, 2002.

Greenblatt, J. B., Jost, J. J., Loewenstein, M., Podolske, J. R., Hurst, D. F., Elkins, J. W., 5 Schauffler, S. M., Atlas, E. L., Herman, R. L., Webster, C. R., Bui, T. P., Moore, F. L., Ray, E. A., Oltmans, S., Vomel, H., Blavier, J.-F., Sen, B., Stachnik, R. A., Toon, G. C., Engle, A., Muller, M., Schmidt, U., Bremer, H., Pierce, R. B., Sinnhuber, B.-M., Chipperfield, M., and Lefevre, F.: Tracer-based determination of vortex descent in the 1999-2000 Arctic winter, J. Geophys. Res., 107(D20), 8279, doi:10.1029/2001JD000937, 2002.

10 Guldberg, A. and Kaas, E.: Danish Meteorological Institute Contribution to the Final Report, in: Project On Tendency Evaluations Using New Techniques to Improve Atmospheric Longterm Simulations (POTENTIALS) - Final Report, edited by: Kaas, E., Danish Meteorological Institute (DMI), Copenhagen, Denmark, 2000.

Hamilton, K.: Effects of an imposed quasi-biennial oscillation in a comprehensive troposphere15 stratosphere-mesosphere general circulation model, J. Atmos. Sci., 55(14), 2393-2418, 1998.

Harries III, J. E., Tuck, A. F., Gordley, L. L., Purcell, P., Stone, K., Bevilacqua, R. M., Gunson, M., Nedoluha, G., and Traub, W. A.: Validation of measurements of water vapor from the Halogen Occultation Experiment (HALOE), J. Geophys. Res., 101(D6), 10205-10216, doi:10.1029/95JD02933, 1996.

Hertzog, A., Basdevant, C., Vial, F., and Mechoso, C. R.: Some results on the accuracy of stratospheric analyses in the Northern Hemisphere inferred from long-duration balloon flights, Q. J. R. Meteorol. Soc., 130, 607-626, 2004.

Jeuken, A. B. M., Siegmund, P. C., Heijboer, L. C., Feichter, J., and Bengtson, L.: On the potential of assimilating meteorological analysis in a climate model for the purpose of model validation, J. Geophys. Res., 101, 16 939-16950, 1996.

Jöckel, P., von Kuhlmann, R., Lawrence, M. G., Steil, B., Brenninkmeijer, C. A. M., Crutzen, P. J., Rasch, P. J., and Eaton, B.: On a fundamental problem in implementing flux-form advection schemes for tracer transport in 3-dimensional general circulation and chemistry transport models, Q. J. R. Meteorol. Soc., 127A, 1035-1052, 2001.

Jöckel, P., Sander, R., and Lelieveld, J.: Technical Note: The Modular Earth Submodel System (MESSy) - a new approach towards Earth System Modeling, Atmos. Chem. Phys., 5, 433444, 2005,

ACPD

5, 961-1006, 2005

\section{Stratospheric temperatures and transport in a nudged GCM}

M. K. van Aalst et al.

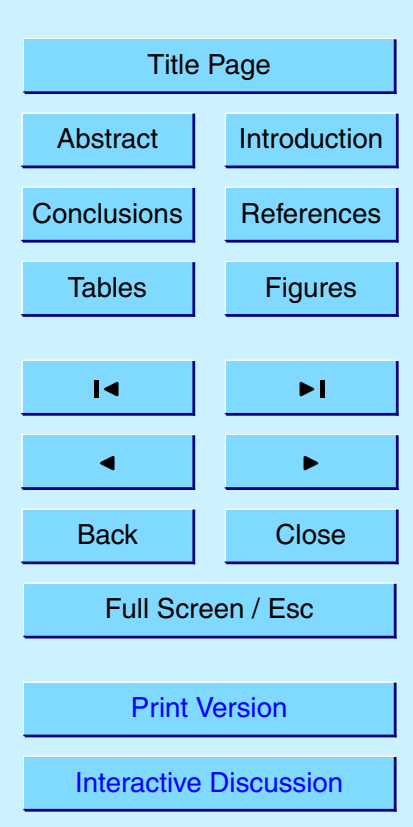

EGU 
SRef-ID: 1680-7324/acp/2005-5-433.

Knudsen B. M.: On the accuracy of analysed low temperatures in the stratosphere, Atmos. Chem. Phys., 3, 1759-1768, 2003,

SRef-ID: 1680-7324/acp/2003-3-1759.

5 Knudsen, B. M., Pommereau, J.-P., Garnier, A., Nunes-Pnharanda, M., Denis, L., Newman, P., Letrenne, G., and Durand, M.: Accuracy of analyzed stratospheric temperatures in the winter Arctic vortex from infrared Montgolfier long-duration balloon flights, 2. Results, J. Geophys. Res., 107(D20), doi:10.1029/2001JD001329, 2002.

Lin, S. J. and Rood, R. B.: Multi-dimensional flux-form semi-Lagrangian transport schemes, Mon. Wea. Rev., 124, 2046-2070, 1996.

Lohmann, U. and Roeckner, E.: Design and performance of a new cloud microphysics scheme developed for the ECHAM4 general circulation model, Clim. Dyn., 12, 557-572, 1996.

Mahowald, N. M., Plumb, R. A., Rasch, P. J., del Corral, J., Sassi, F., and Heres, W.: Stratospheric transport in a 3-dimensional isentropic coordinate model, J. Geophys. Res, 107(D15), doi:10.1029/2001JD1313, 2002.

Manney, G. L., Sabutis, J. L., Pawson, S., Santee, M. L., Naujokat, B., Swinbank, R., Gelman, M. E., and Ebisuzaki, W.: Lower stratospheric temperature differences between meteorological analyses in two cold Arctic winters and their impact on polar processing studies, J. Geophys. Res., 108(D5), 8328, doi:10.1029/2001JD001149, 2003.

Manzini, E. and McFarlane, N. A.: The effect of varying the source spectrum of a gravity wave parameterization in a middle atmosphere general circulation model, J. Geophys. Res., 103, 31523-31 539, 1998.

Manzini, E., McFarlane, N. A., and McLandress, C.: Impact of the Doppler spread parameterization on the simulation of the middle atmosphere circulation using the MA/ECHAM4 general circulation model, J. Geophys. Res., 102(D22), 25 751-25 762, doi:10.1029/97JD01096, 1997.

Manzini, E., Steil, B., Brühl, C., Giorgetta, M. A., and Krüger, K.: A new interactive chemistryclimate model: 2 . Sensitivity of the middle atmosphere to ozone depletion and increase in greenhouse gases and implications for recent stratospheric cooling, J. Geophys. Res.,

Marquardt, C. and Naujokat, B.: An update of the equatorial QBO and its variability, 1st SPARC General Assembly, Melbourne Australia, WMO/TD-No. 814, 1, 87-90, 1997.

Morcrette, J.-J., Clough, S. A., Mlawer, E. J., and lacono, M. J.: Impact of a validated radiative

5, 961-1006, 2005

\section{Stratospheric temperatures and transport in a nudged GCM}

M. K. van Aalst et al.

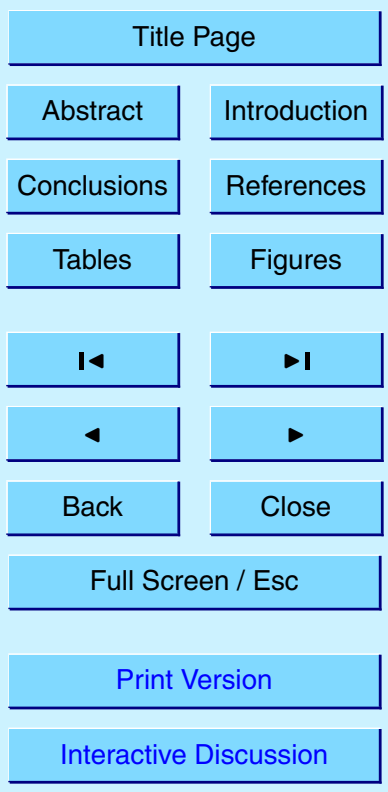

EGU 
transfer scheme, RRTM, on the ECMWF model climate and 10-day forecasts, Technical Memorandum 252, ECMWF, Reading, UK, 1998.

Mote, P. W., Rosenlof, K. H., Mclntyre, M. E, Carr, E. S., Gille, J. C., Holton, J. R., Kinnersley, J. S., Pumphrey, H. C., Russell III, J. M., and Waters, J. W.: An atmospheric tape recorder: the 5 imprint of tropical tropopause temperatures on stratospheric water vapor, J. Geophys. Res., 101, 3989-4006, 1996.

Naujokat, B.: An update of the observed quasi-biennial oscillation of the stratospheric winds over the tropics, J. Atmos. Sci., 43, 1873-1877, 1986.

Naujokat, B., Krüger, K., Matthes, K., Hoffmann, J., Kunze, M., and Labitzke, K.: The early major warming in December 2001 - exceptional?, Geophys. Res. Lett., 29(21), 2023, doi:10.1029/2002GL015316, 2002.

Park, J. H., Russell III, J. M., Gordley, L. L., Drayson, S. R., Benner, C. D., McInerney, J., Gunson, M. R., Toon, G. G., Sen, B., Blavier, J.-F., Webster, C. R., Zipf, E. C., Erdman, P., Schmidt, U., and Schiller, C.: Validation of Halogen Occultation Experiment $\mathrm{CH} 4$ Measurements from the UARS, J. Geophys. Res., 101, 10 183-10203, 1996.

Pawson, S., Kodera, K., Hamilton, K., Shepherd, T. G., Beagley, S. R., Boville, B. A., Farrara, J. D., Fairlie, T. D. A., Kitoh, A., Lahoz, W. A., Langematz, U., Manzini, E., Rind, D. H., Scaife, A., Shibata, K., Simon, P., Swinbank, R., Takacs, L., Wilson, R. J., Al-Saadi, J. A., Amodei, M., Chiba, M., Coy, L., deGrandpré, J., Eckman, R. S., Fiorino, M., Grose, W. L., Koide, H., Koshyk, J. N., Li, D., Lerner, J., Mahlman, J. D., McFarlane, N. A., Mechoso, C. R., Molod, A., O'Neill, A., Pierce, R. B., Randel, W. J., Rood, R. B., and Wu, F.: The GCM-Reality Intercomparison Project for SPARC (GRIPS): Scientific Issues and Initial Results, Bull. Am. Meteorol. Soc., 81, 781-796, 2000.

Pommereau, J.-P., Garnier, A., Knudsen, B. M., Letrenne, G., Durand, M., Nunes-Pinharanda, M., Denis, L., Vial, F., Hertzog, A., and Cairo, F.: Accuracy of analyzed stratospheric temperatures in the winter arctic vortex from infrared Montgolfier long duration balloon flights, 1 , Measurements, J. Geophys. Res., 107(D20), doi:10.1029/2001JD001379, 2002.

Prather, M.: Numerical advection by conservation of second-order moments, J. Geophys. Res., 91, 6671-6681, 1986.

30 Rasch, P. J. and Lawrence, M.: Recent Developments in Transport Methods at NCAR, in: MPI Workshop on conservative transport schemes, MPI-report 265, Max-Planck-Institute for Meteorology, Hamburg, Germany, 1998.

Rasch, P. J. and Williamson, D. L.: On shape-preserving interpolation and semi-Lagrangian
ACPD

5, 961-1006, 2005

\section{Stratospheric temperatures and transport in a nudged GCM}

M. K. van Aalst et al.

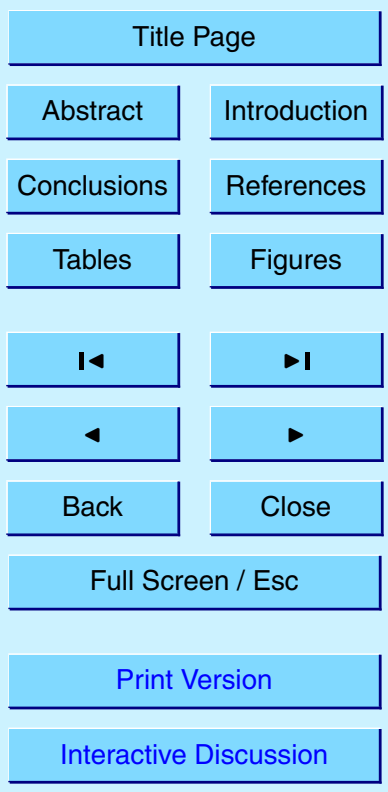


transport, SIAM, J. Sci. Stat. Comput., 11, 656-687, 1990.

Rasch, P. J., Boville, B. A., and Brasseur, G. P.: A threedimensional general circulation model with coupled chemistry for the middle atmosphere, J. Geophys. Res., 100, 9041-9071, 1995.

5 Roeckner, E., Arpe, K., Bengtsson, L., Christoph, M., Claussen, M., Dümenil, L., Esch, M., Giorgetta, M., Schlese, U., and Schulzweida, U.: The atmospheric general circulation model ECHAM4: Model description and simulation of present-day climate, MPI Report 218, Hamburg, Germany, 1996.

Roeckner, E., Bäuml, G., Bonaventura, L., Brokopf, R., Esch, M., Giorgetta, M., Hagemann, S., Kirchner, I., Kornblueh, L., Manzini, E., Rhodin, A., Schlese, U., Schulzweida, U., and Tompkins, A.: The atmospheric general circulation model ECHAM 5. PART I: Model description, MPI-Report 349, Hamburg, Germany, 2003.

Roeckner, E., Brokopf, R., Esch, M., Giorgetta, M., Hagemann, S., Kornblueh, L., Manzini, E., Schlese, U., and Schulzweida, U.: The atmospheric general circulation model ECHAM 5, PART II: Sensitivity of Simulated Climate to Horizontal and Vertical Resolution, MPI-Report 354, Hamburg, Germany, 2004.

Russell, G. M. and Lerner, J. A.: A new finite-differencing scheme for the tracer transport equation, J. Appl. Meteorol., 20, 1483-1498, 1993.

Russell III, J. M., Gordley, L. L., Park, J. H., Drayson, S. R., Hesketh, D. H., Cicerone, R. J., Tuck, A. F., Frederick, J. E., Harries, J. E., and Crutzen, P. J.: The Halogen Occultation Experiment, J. Geophys. Res., 98, 10777-10797, 1993.

Schulz, J.-P., Dümenil, L., and Polcher, J.: On the land surface-atmosphere coupling and its impact in a single-column atmospheric model, J. Appl. Meteorol., 40, 642-663, 2001.

Simmons, A. J. and Gibson, J. K.: The ERA40 Project Plan, ERA40 Project Report Series No. 1, ECMWF, Reading, UK, 2000.

Simmons, A. J., Burridge, D. M., Jarraud, M., Girard, C., and Wergen, W.: The ECMWF medium-range prediction model: Development of the numerical formulations and the impact of increased resolution, Meteorol. Atmos. Phys., 40, 28-60, 1989.

Simmons, A., Hortal, M., Kelly, G., McNally, A., Untch, A., and Uppala, S.: ECMWF analyses and forecasts of stratospheric winter polar vortex break-up: September 2002 in the Southern Hemisphere and related events, J. Atmos. Sci., in press, 2005.

Steil, B., Brühl, C., Manzini, E., Crutzen, P. J., Lelieveld, J., Rasch, P. J., Roeckner, E., and Krüger, K.: A new interactive chemistry climate model, I: Present day climatology and inter-

\section{ACPD}

5, 961-1006, 2005

\section{Stratospheric temperatures and transport in a nudged GCM}

M. K. van Aalst et al.

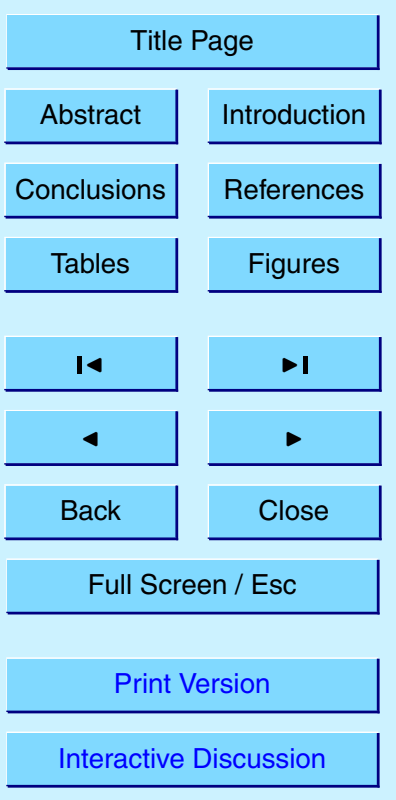

EGU 
annual variability of the middle atmosphere using the model and 9 years of HALOE/UARS data, J. Geophys. Res., 108(D9), 4290, doi:10.1029/2002JD002971, 2003.

Van Aalst, M. K., van den Broek, M. M. P., Bregman, A., Brühl, C., Steil, B., Toon, G. C., Garcelon, S., Hansford, G. M., Jones, R. L., Gardiner, T. D., Roelofs, G. J., Lelieveld, J., and $5 \quad$ Crutzen, P. J.: Trace gas transport in the 1999/2000 Arctic winter; comparison of nudged GCM runs with observations, Atmos. Chem. Phys., 4, 81-93, 2004a,

SRef-ID: 1680-7324/acp/2004-4-81.

Van den Broek, M. M. P., van Aalst, M. K., Bregman, A., Krol, M., Lelieveld, J., Toon, G. C., Garcelon, S., Hansford, G. M., Jones, R. L., and Gardiner, T. D.: The impact of model grid zooming on tracer transport in the 1999/2000 Arctic polar vortex, Atmos. Chem. Phys., 3, 1833-1847, 2003,

SRef-ID: 1680-7324/acp/2003-3-1833.

\section{ACPD}

5, 961-1006, 2005

\section{Stratospheric temperatures and transport in a nudged GCM}

M. K. van Aalst et al.

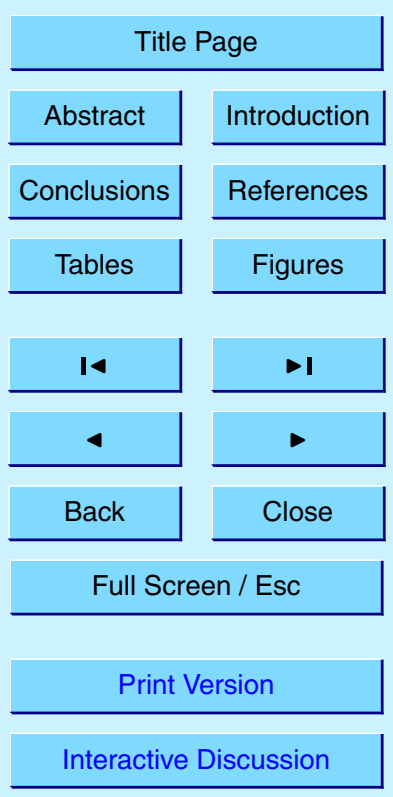




\section{ACPD}

$5,961-1006,2005$

\section{Stratospheric} temperatures and transport in a nudged GCM

M. K. van Aalst et al.

Table 1. Relative difference between MAECHAM5/MESSy and ECMWF in area with temperatures lower than $190 \mathrm{~K}$ during the month of August.

\begin{tabular}{lll}
\hline & $54 \mathrm{hPa}$ & $70 \mathrm{hPa}$ \\
\hline 2000 & $12 \%$ & $9 \%$ \\
2001 & $22 \%$ & $48 \%$ \\
2002 & $8 \%$ & $9 \%$ \\
2003 & $10 \%$ & $0 \%$ \\
\hline
\end{tabular}

Title Page

\begin{tabular}{c|c} 
Abstract & Introduction \\
Conclusions & References \\
\cline { 2 - 2 } Tables & Figures \\
\hline
\end{tabular}

14

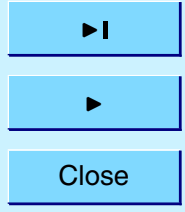

Full Screen / Esc

Print Version

Interactive Discussion 


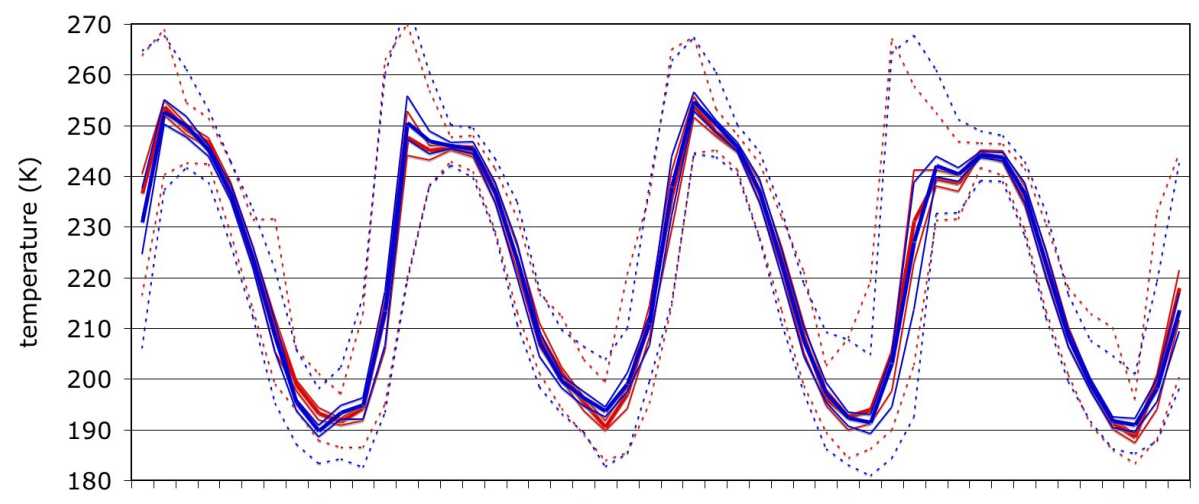

ACPD

5, 961-1006, 2005
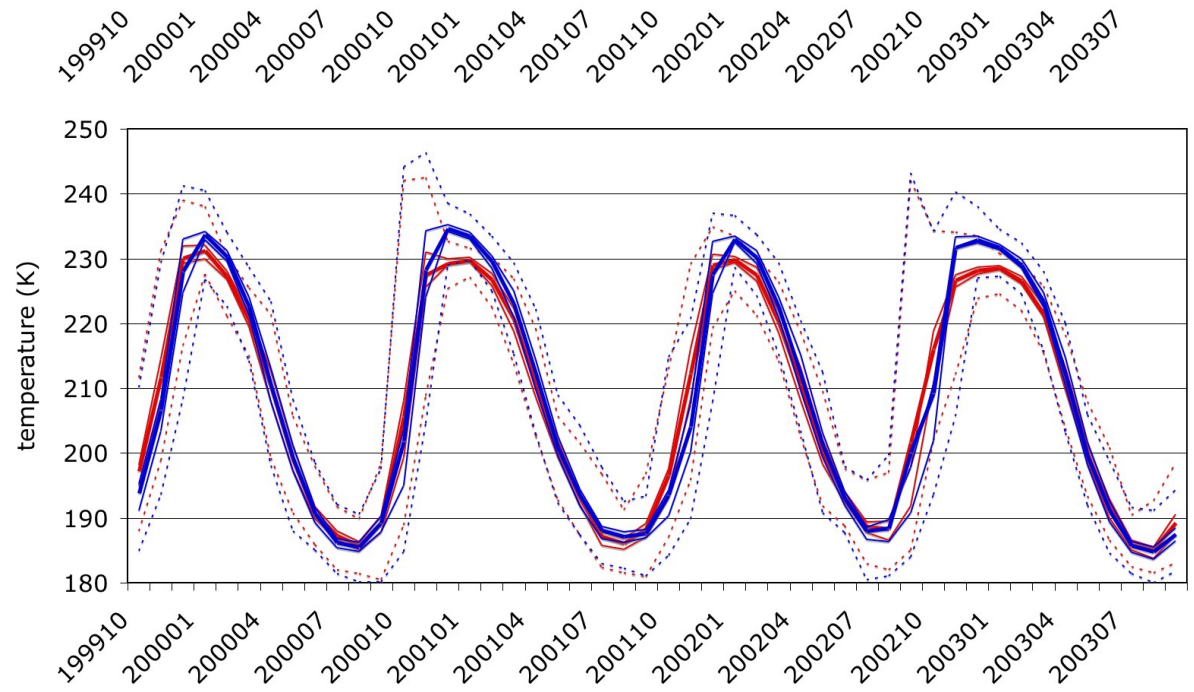

Title Page

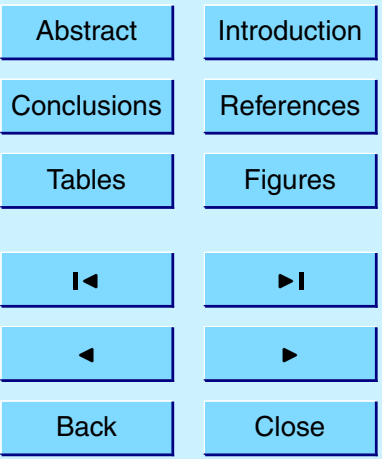

Full Screen / Esc

Fig. 1. Monthly temperatures $(\mathrm{K})$ at $80^{\circ} \mathrm{S}, 10 \mathrm{hPa}$ (top) and $70 \mathrm{hPa}$ (bottom), for MAECHAM5/MESSy (red) and ECMWF (blue). Thick solid lines represent the mean, colored dashed lines the 33 and 66 percentiles, and black dashed lines the minimum and maximum values.

Print Version

Interactive Discussion 


\section{ACPD}

5, 961-1006, 2005

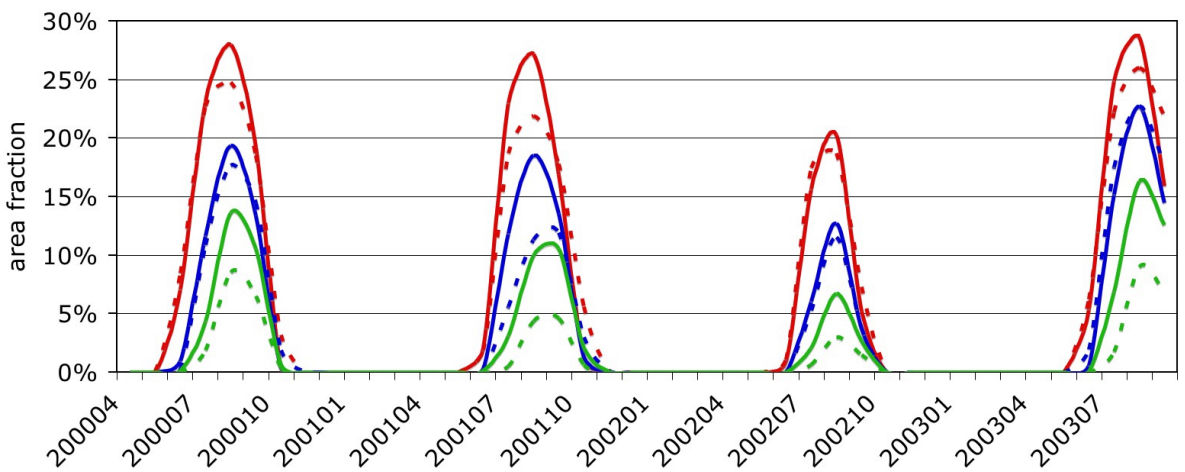

Fig. 2. Area-weighted fraction of grid points south of $50^{\circ} \mathrm{S}$ with temperatures below $190 \mathrm{~K}$ at $54 \mathrm{hPa}$ (red), $70 \mathrm{hPa}$ (blue) and $89 \mathrm{hPa}$ (green), for MA-ECHAM (solid lines) and ECMWF (dashed lines).
Stratospheric temperatures and transport in a nudged GCM

M. K. van Aalst et al.

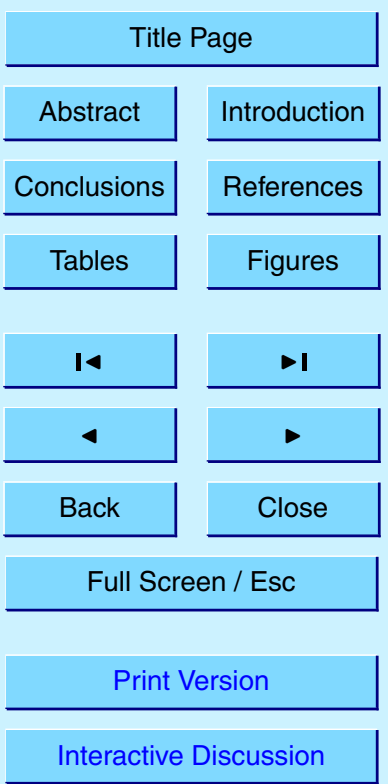




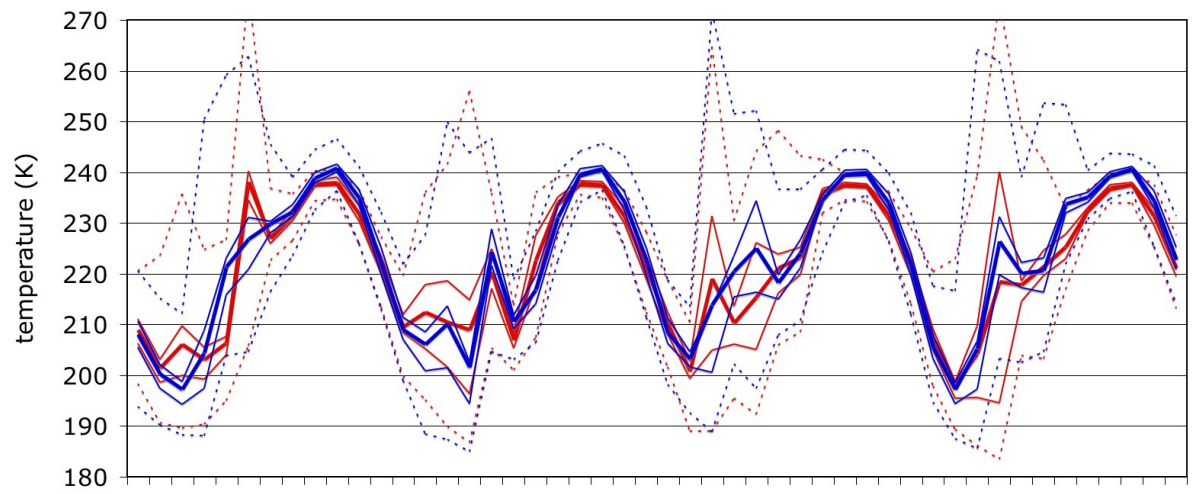

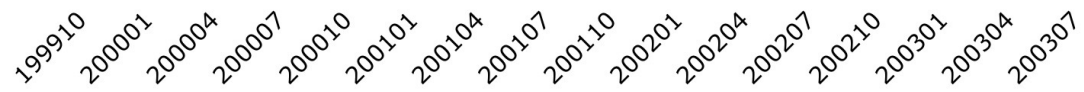

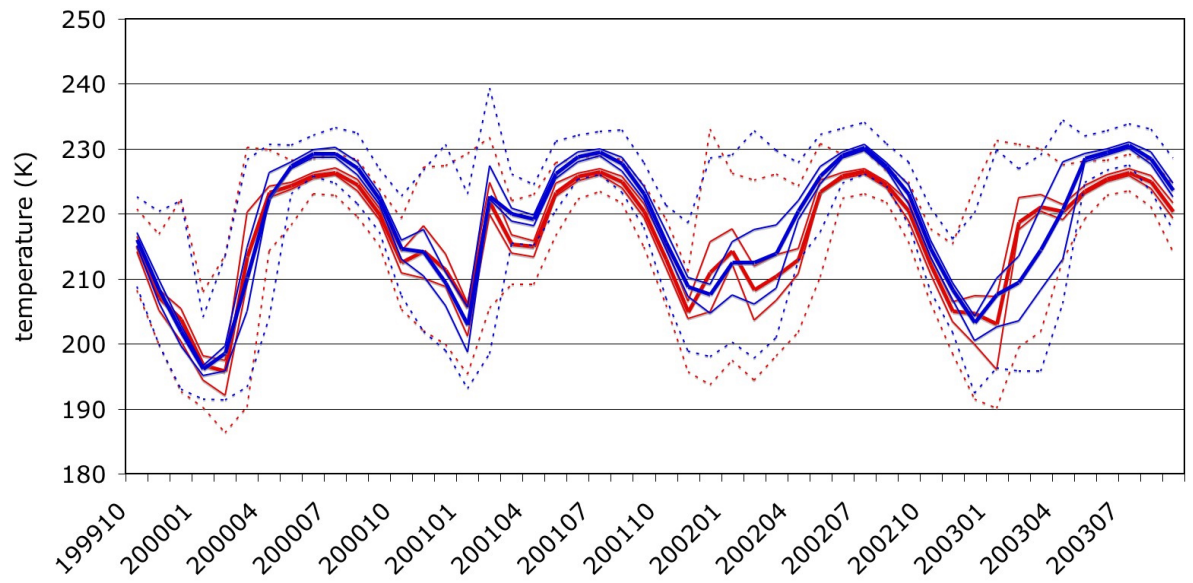

Fig. 3. Monthly temperatures $(\mathrm{K})$ at $80^{\circ} \mathrm{N}, 10 \mathrm{hPa}$ (top) and $70 \mathrm{hPa}$ (bottom), represented as in Fig. 1.

\section{ACPD}

5, 961-1006, 2005

Stratospheric temperatures and transport in a nudged GCM

M. K. van Aalst et al.

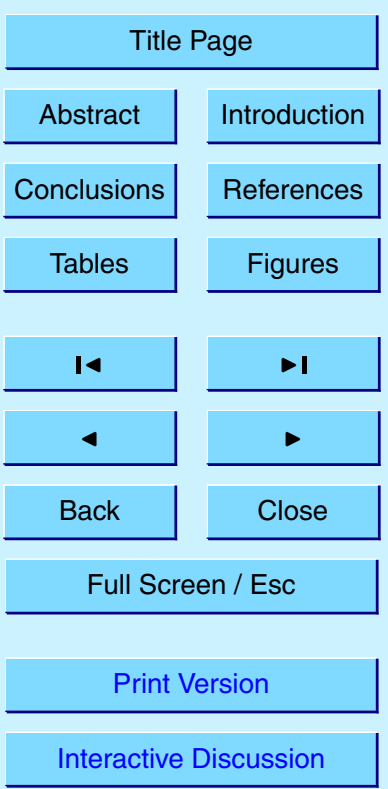

EGU 


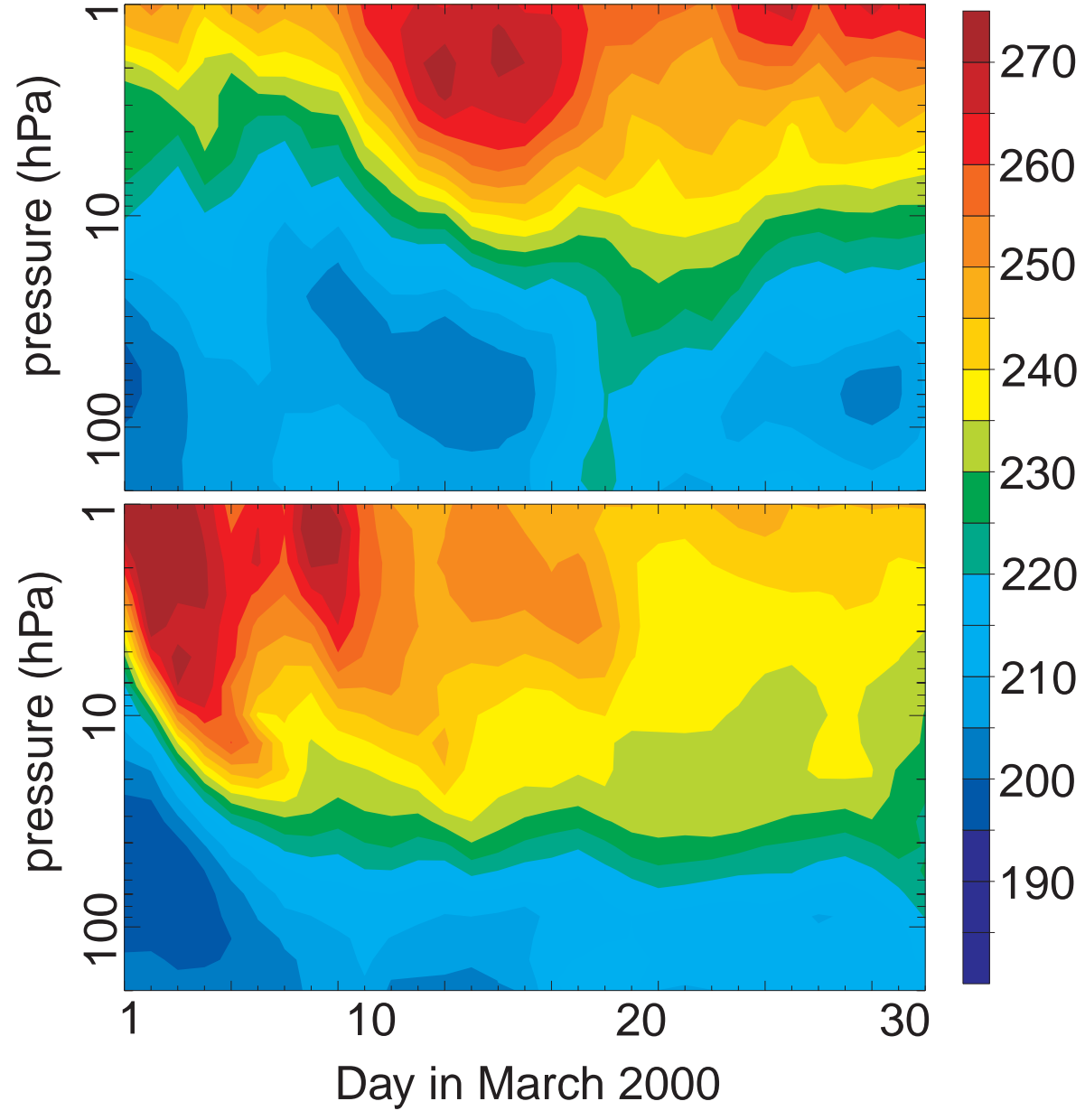

Fig. 4. Time series of temperatures $(K)$ at the North Pole during March 2000 in ECMWF analyses (top) and simulated by MAECHAM5/MESSy (bottom).
ACPD

5, 961-1006, 2005

Stratospheric temperatures and transport in a nudged GCM

M. K. van Aalst et al.

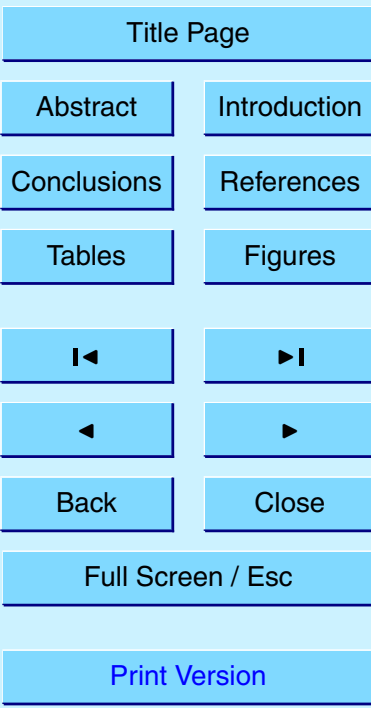

Interactive Discussion 


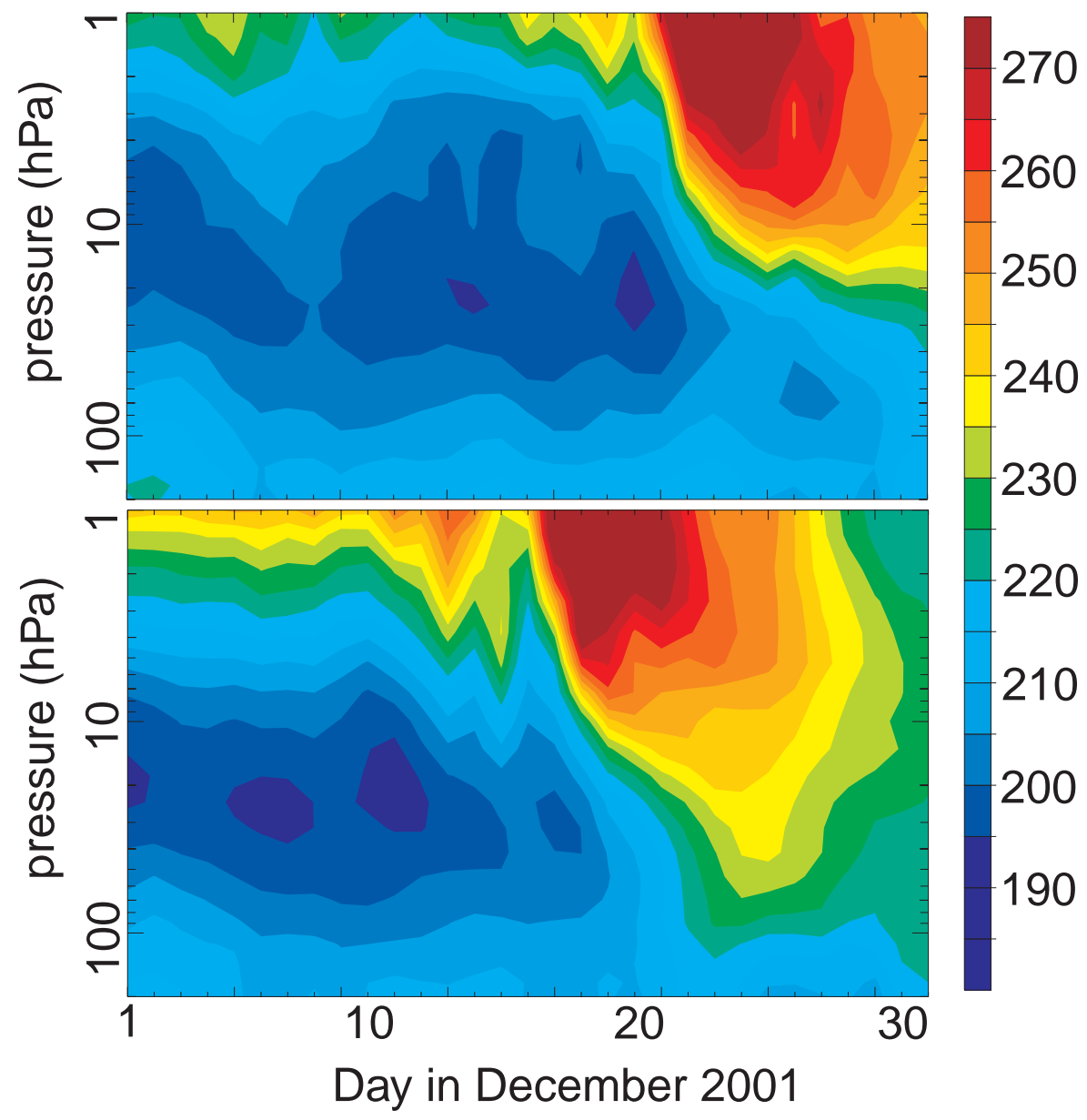

Fig. 5. Time series of temperatures $(K)$ at the North Pole during December 2001 in ECMWF analyses (top) and simulated by MAECHAM5/MESSy (bottom).
ACPD

5, 961-1006, 2005

Stratospheric temperatures and transport in a nudged GCM

M. K. van Aalst et al.

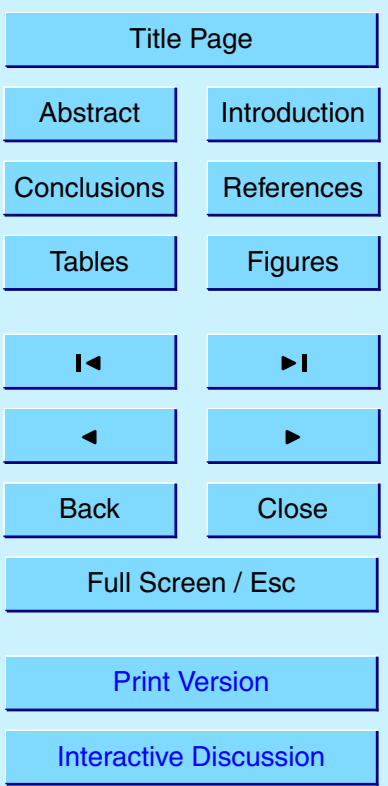

EGU 


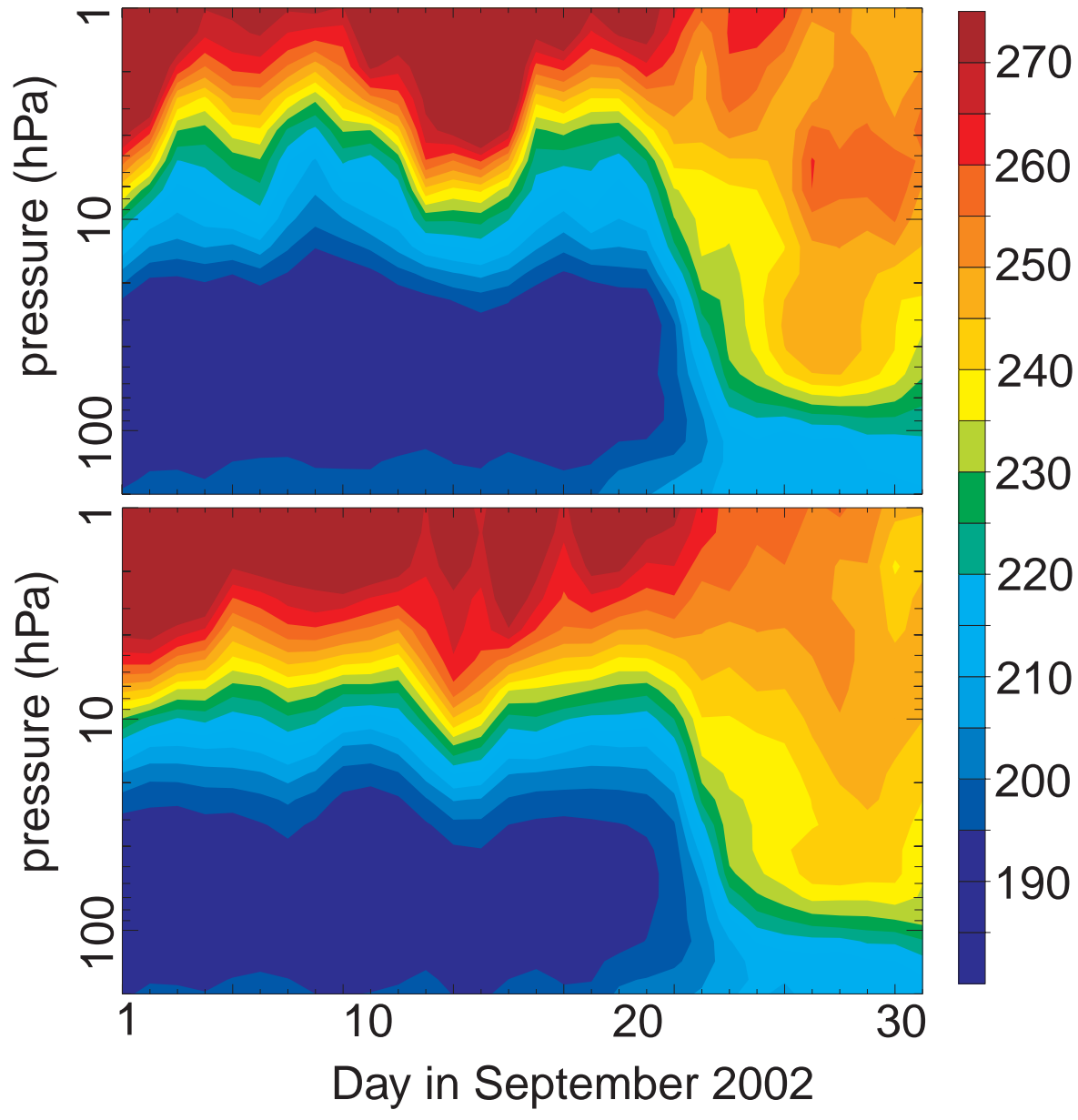

Fig. 6. Time series of temperatures $(K)$ at the South Pole during September 2002 in ECMWF analyses (top) and simulated by MAECHAM5/MESSy (bottom).

\section{ACPD}

5, 961-1006, 2005

Stratospheric temperatures and transport in a nudged GCM

M. K. van Aalst et al.

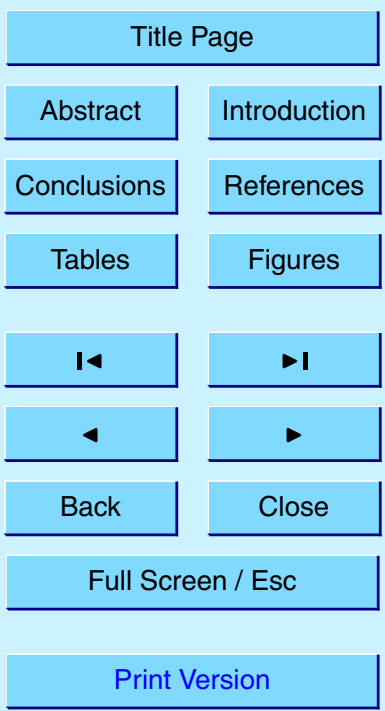

Interactive Discussion 


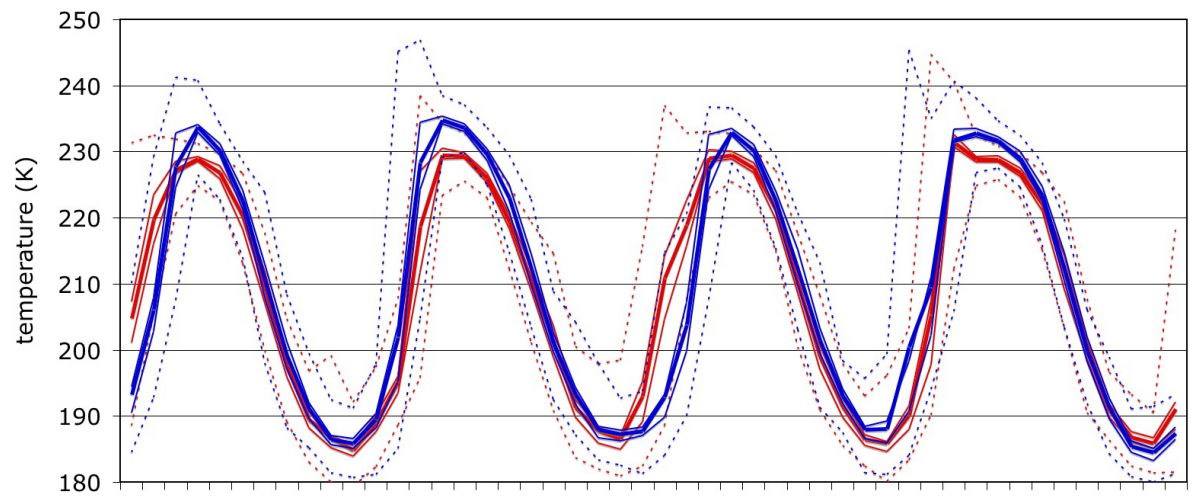

ACPD

5, 961-1006, 2005

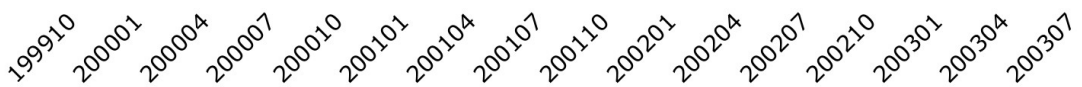

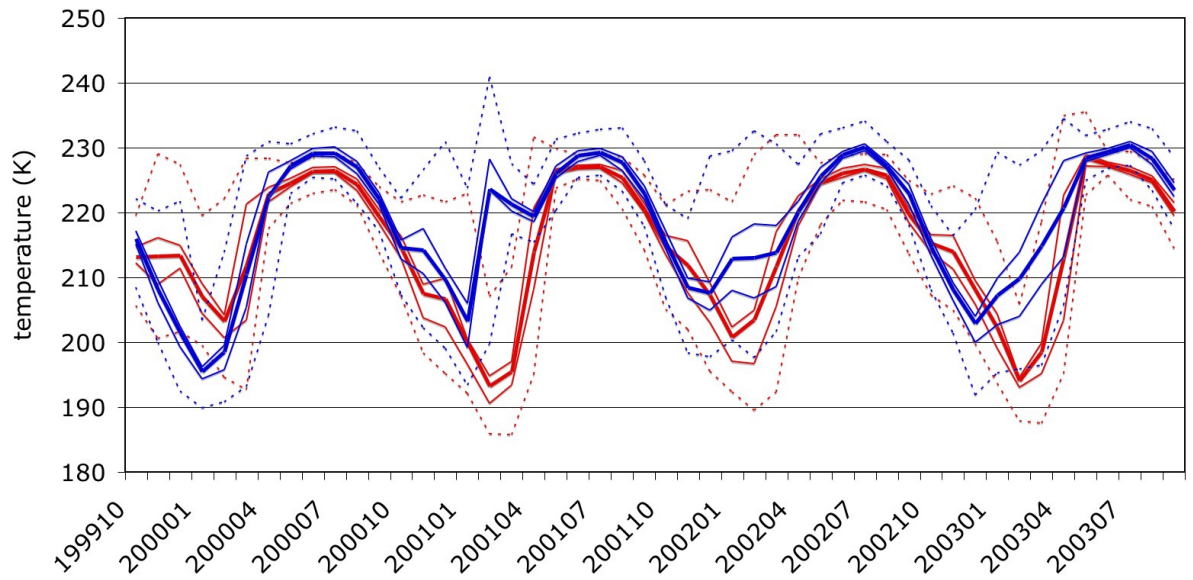

Title Page

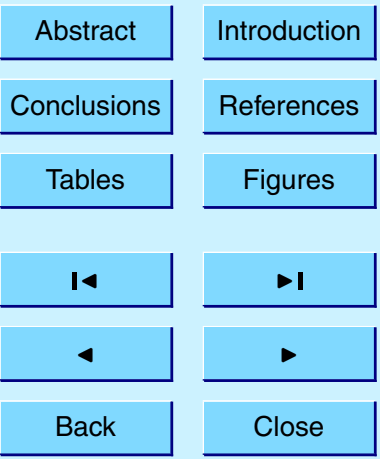

Full Screen / Esc

Fig. 7. Monthly temperatures (K) at $80^{\circ} \mathrm{S}$ (top) and $80^{\circ} \mathrm{N}$ (bottom), both at $70 \mathrm{hPa}$, for a run

Print Version without tropospheric nudging, represented as in Fig. 1.

Interactive Discussion 


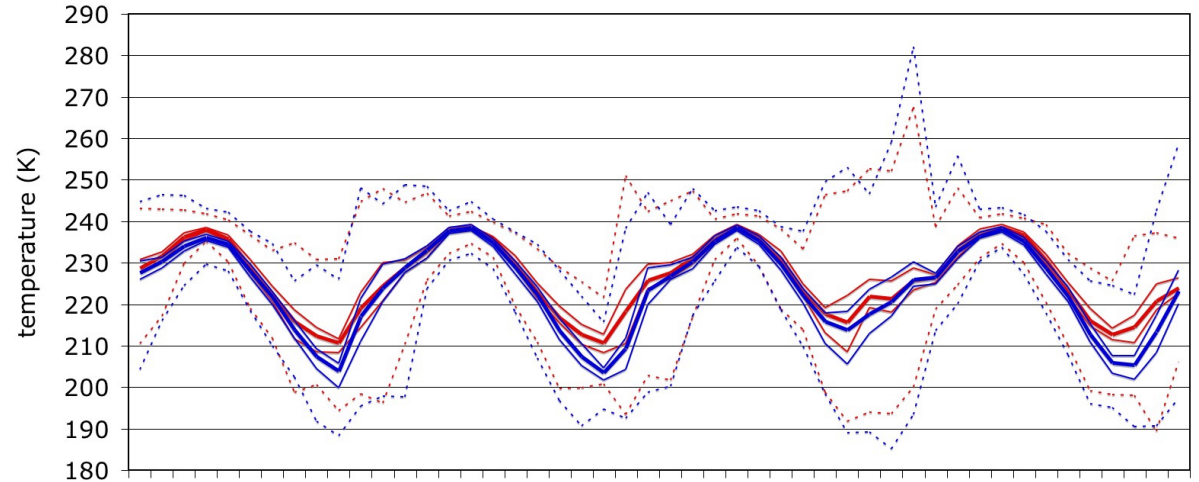

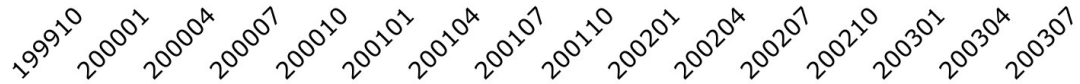

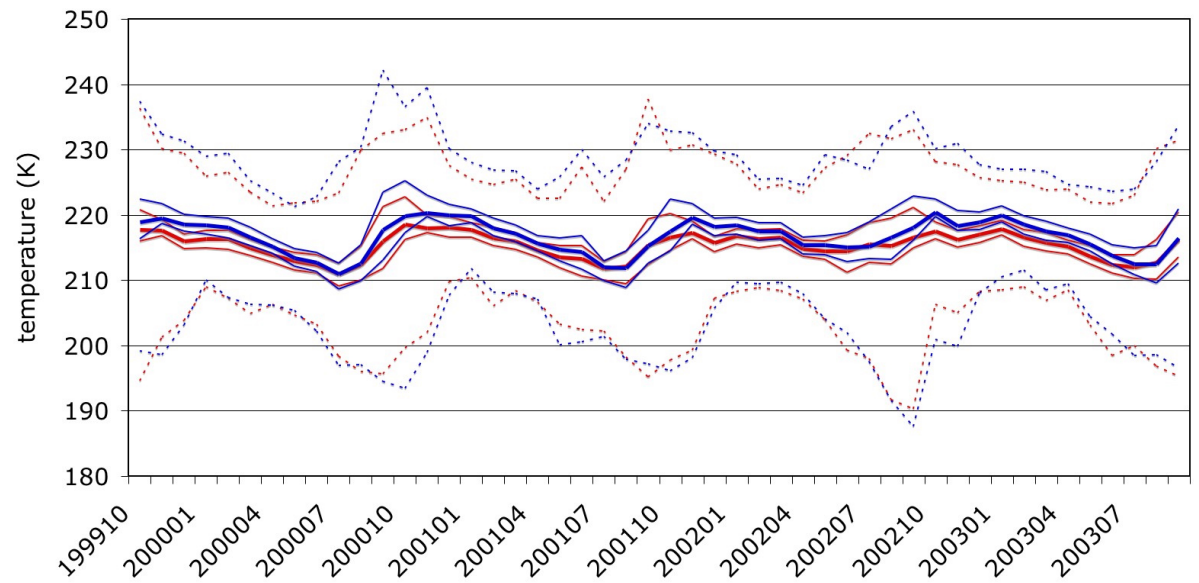

Fig. 8. Monthly temperatures (K) at $50^{\circ} \mathrm{S}, 10 \mathrm{hPa}$ (top) and $70 \mathrm{hPa}$ (bottom), represented as in Fig. 1.

\section{ACPD}

5, 961-1006, 2005

Stratospheric temperatures and transport in a nudged GCM

M. K. van Aalst et al.

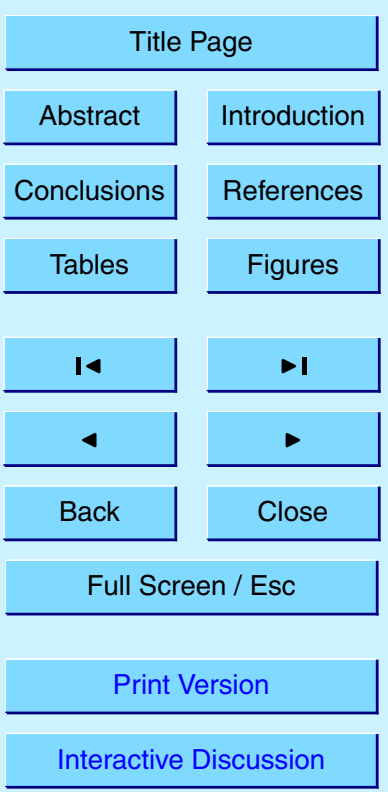

EGU 


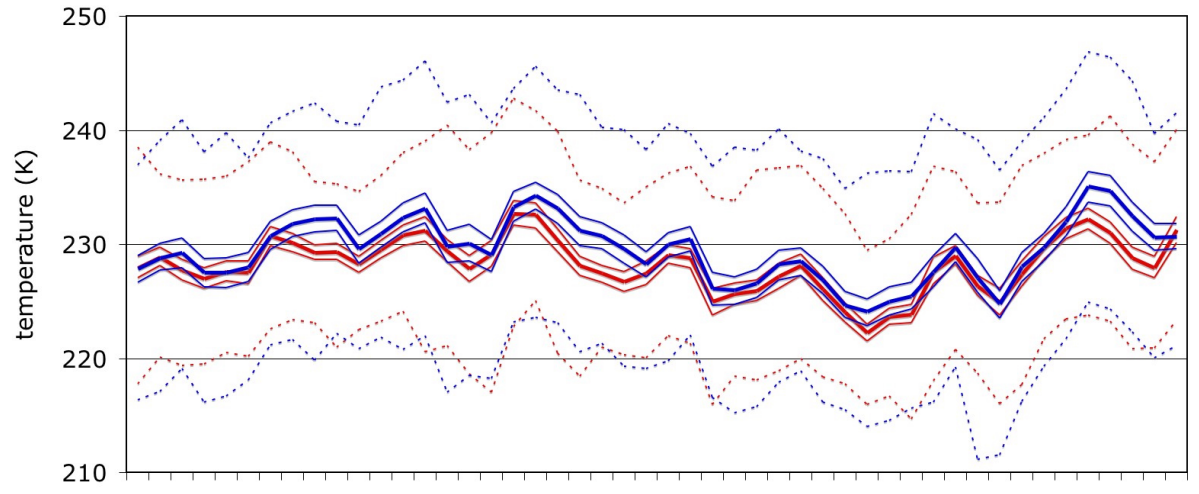

ACPD

5, 961-1006, 2005

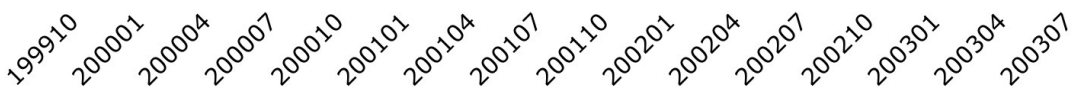

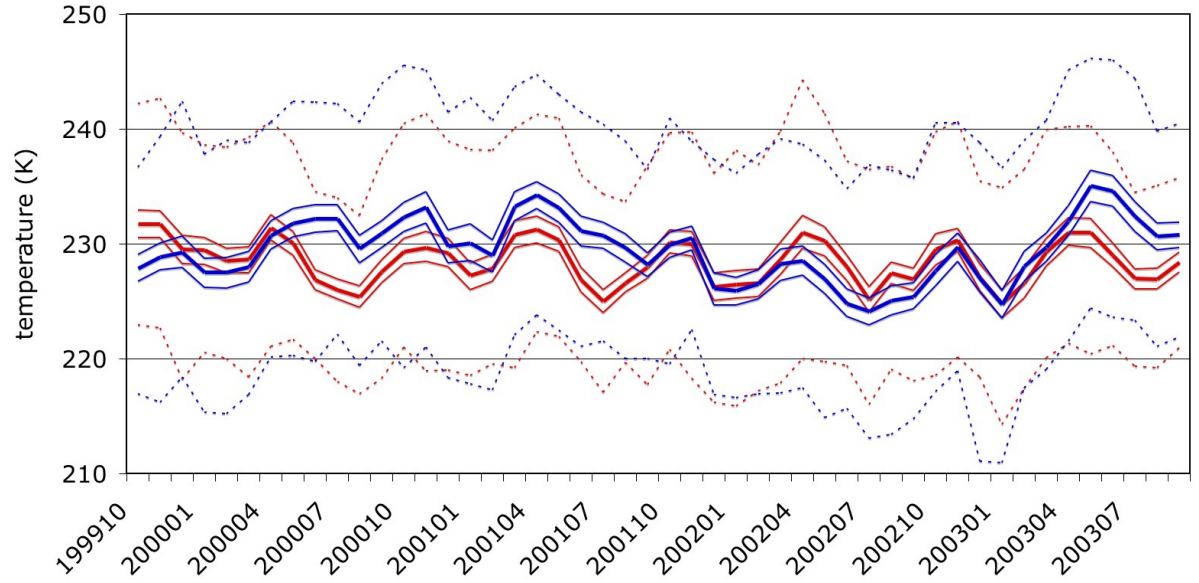

Title Page

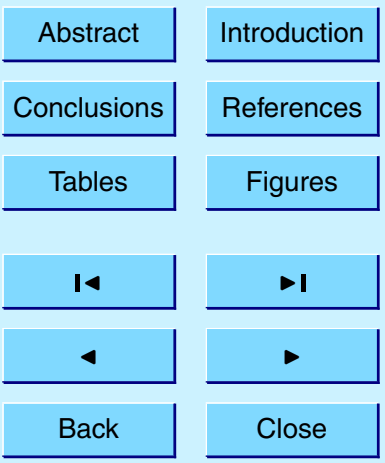

Full Screen / Esc

Print Version

Fig. 9. Monthly temperatures at the equator $(\mathrm{K})$, at $10 \mathrm{hPa}$, for a run with (top) and without $\mathrm{QBO}$ nudging (bottom), represented as in Fig. 1. 


\section{ACPD}

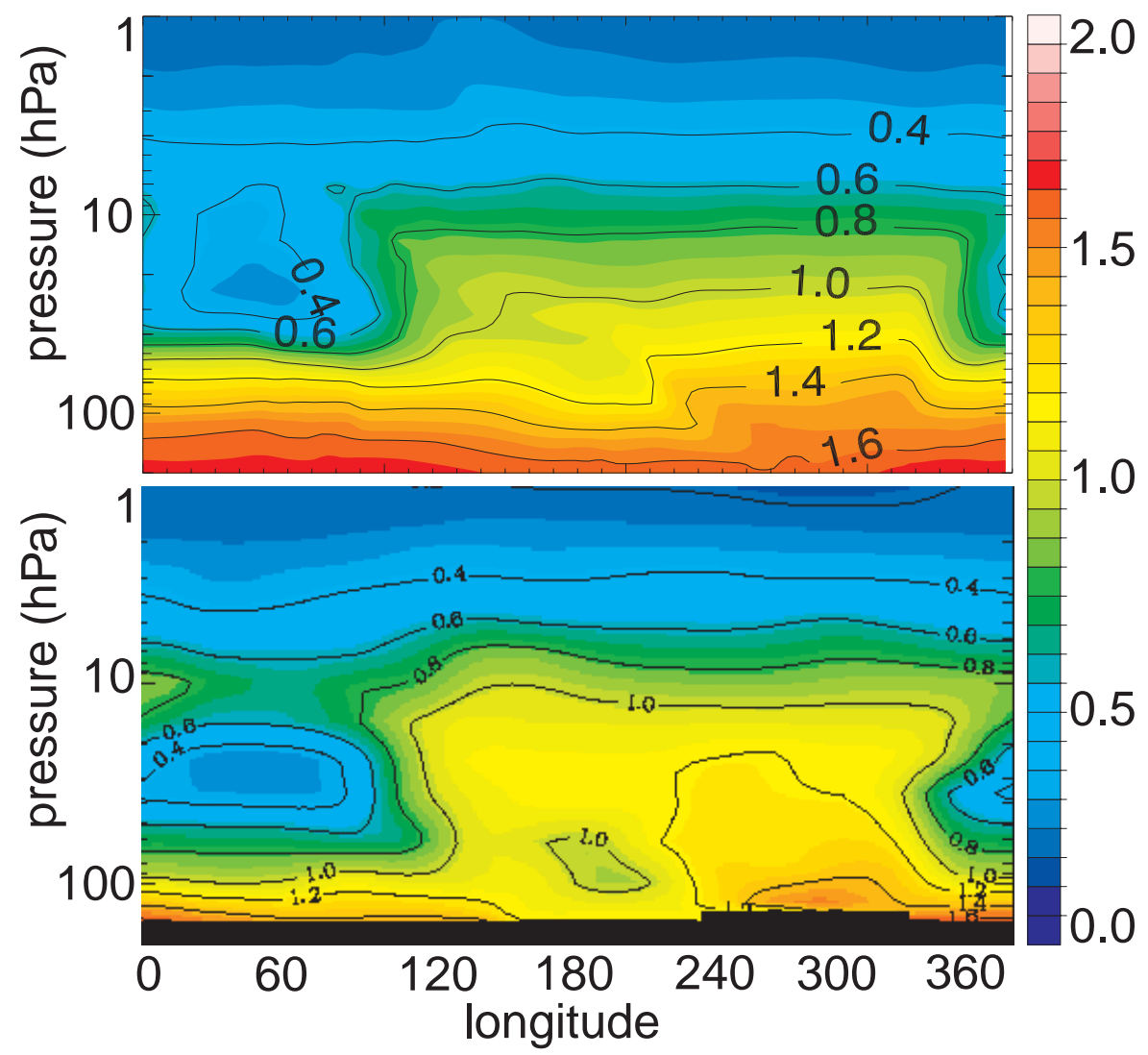

5, 961-1006, 2005

Stratospheric temperatures and transport in a nudged GCM

M. K. van Aalst et al.

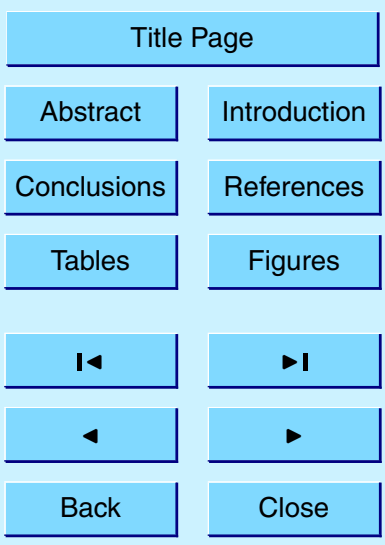

Full Screen / Esc

Print Version

Fig. 10. $\mathrm{CH}_{4}$ mixing ratios (ppmv) on 3 November 2000 at $74^{\circ} \mathrm{S}$, simulated by MAECHAM5/MESSy (top) and observed by HALOE (bottom).

Interactive Discussion 


\section{ACPD}

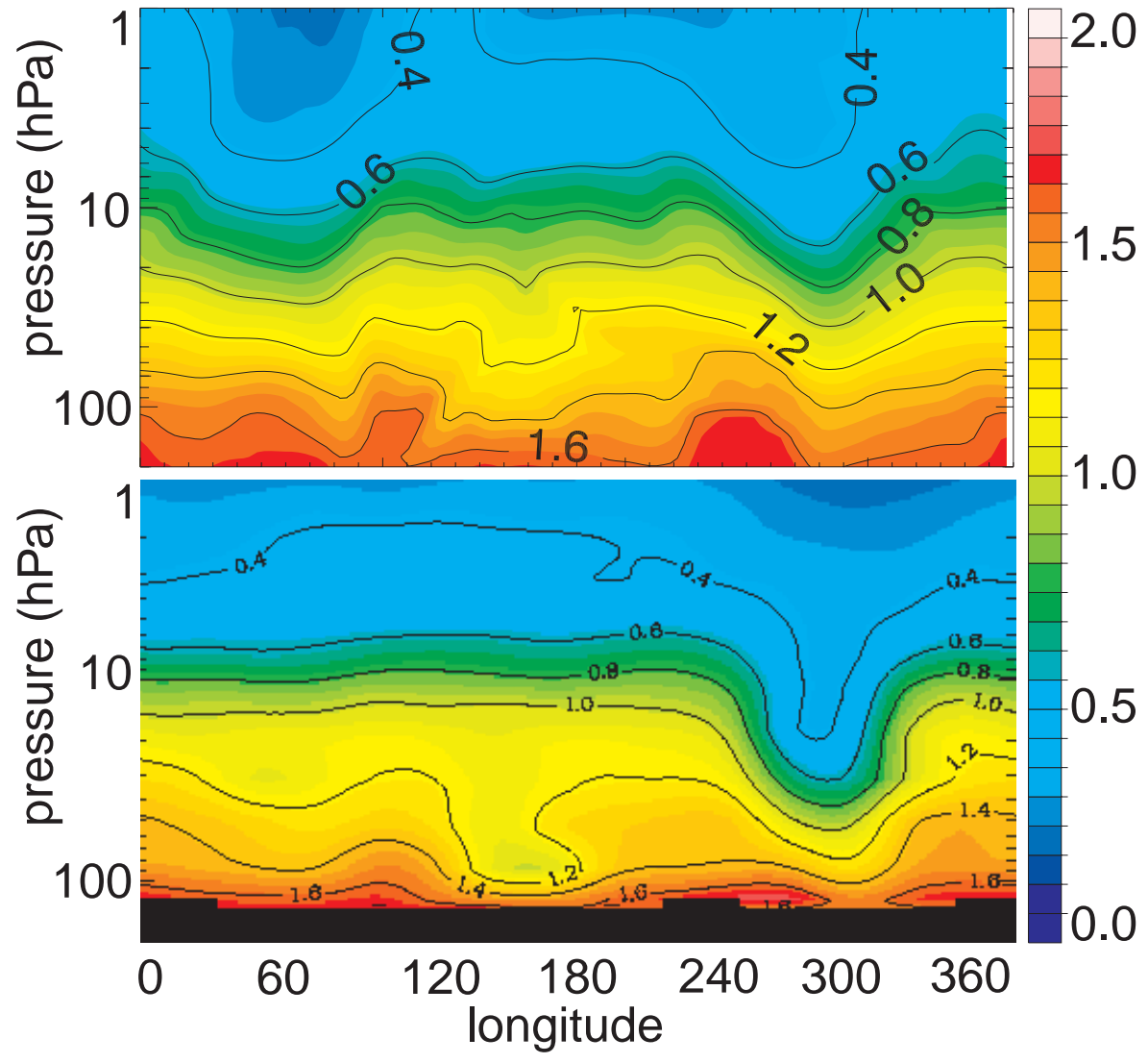

5, 961-1006, 2005

Stratospheric temperatures and transport in a nudged GCM

M. K. van Aalst et al.

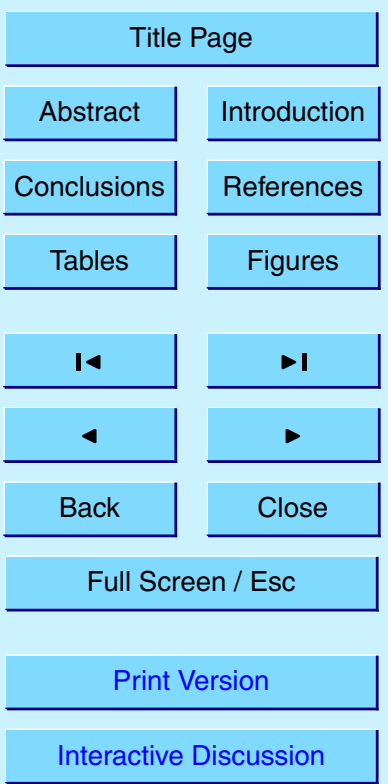

Fig. 11. $\mathrm{CH}_{4}$ mixing ratios (ppmv) on 20 February 2000 at $56^{\circ} \mathrm{N}$, simulated by MAECHAM5/MESSy (top) and observed by HALOE (bottom). 


\section{ACPD}

5, 961-1006, 2005

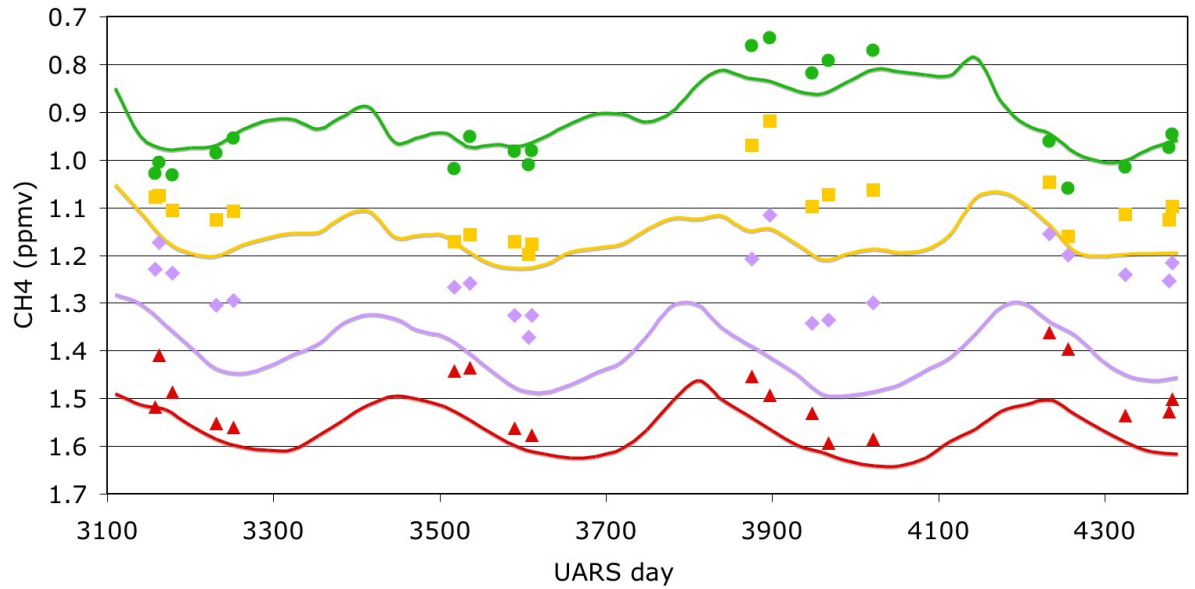

\section{temperatures and transport in a nudged GCM}

Stratospheric

M. K. van Aalst et al.

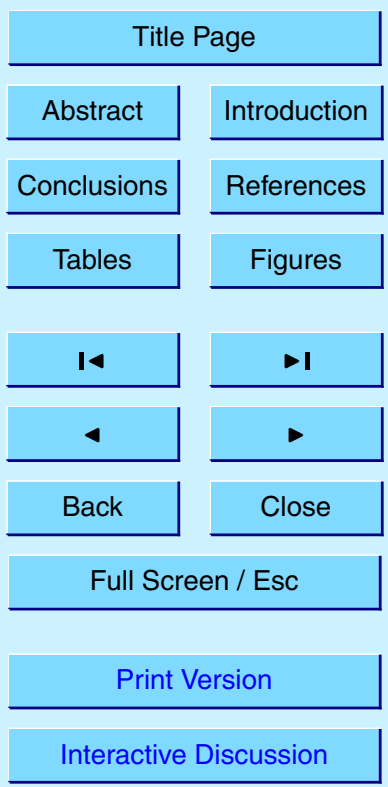

Fig. 12. $\mathrm{CH}_{4}$ concentrations at $70^{\circ} \mathrm{N}$ (ppmv) versus time (days). Solid lines represent monthly mean MAECHAM5/MESSy $\mathrm{CH}_{4}$ mixing ratios at, from top to bottom, $24 \mathrm{hPa}$ (green), $42 \mathrm{hPa}$ (yellow), $70 \mathrm{hPa}$ (lavender) and $113 \mathrm{hPa}$ (red). The marks represent HALOE measurements, in the same colors as the corresponding model levels. Time is given in UARS days; day 3100 corresponds to 7 March 2000; day 4300 to 20 June 2003. 


\section{ACPD}

5, 961-1006, 2005

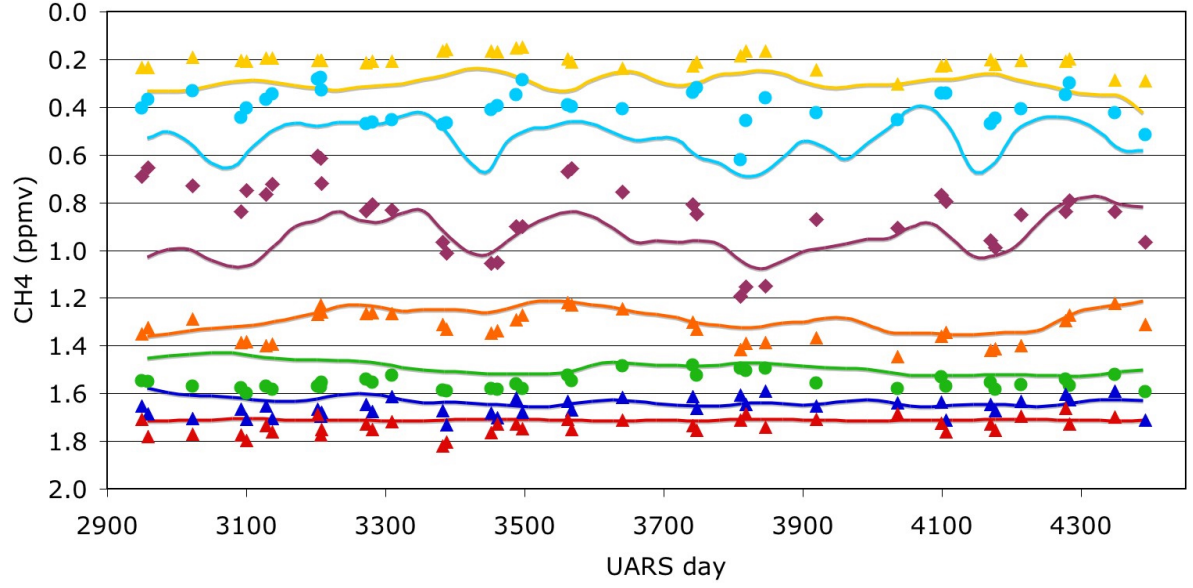

Fig. 13. $\mathrm{CH}_{4}$ concentrations at the equator (ppmv) versus time (days). Solid lines represent monthly mean zonal mean MAECHAM5/MESSy $\mathrm{CH}_{4}$ mixing ratios at, from top to bottom, $0.4 \mathrm{hPa}$ (yellow), $1.3 \mathrm{hPa}$ (blue), $4 \mathrm{hPa}$ (purple), $10 \mathrm{hPa}$ (orange), $24 \mathrm{hPa}$ (green), $54 \mathrm{hPa}$ (blue), and $113 \mathrm{hPa}$ (red). The marks represent HALOE measurements, in the same colors as the corresponding model levels. Time is given in UARS days; day 2900 corresponds to 20 August 2000; day 4300 to 20 June 2003.
Stratospheric temperatures and transport in a nudged GCM

M. K. van Aalst et al.

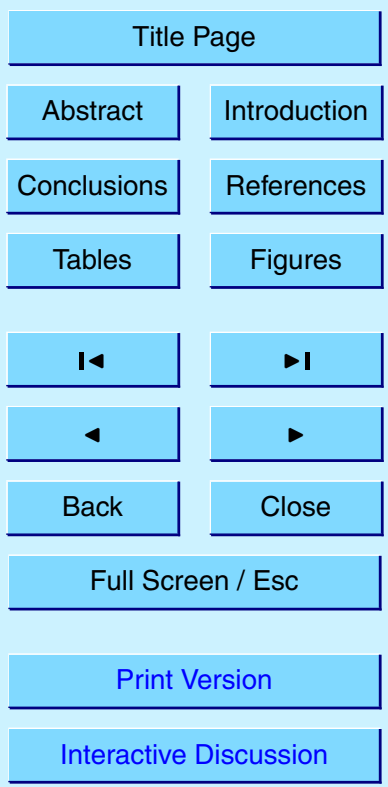




\section{ACPD}

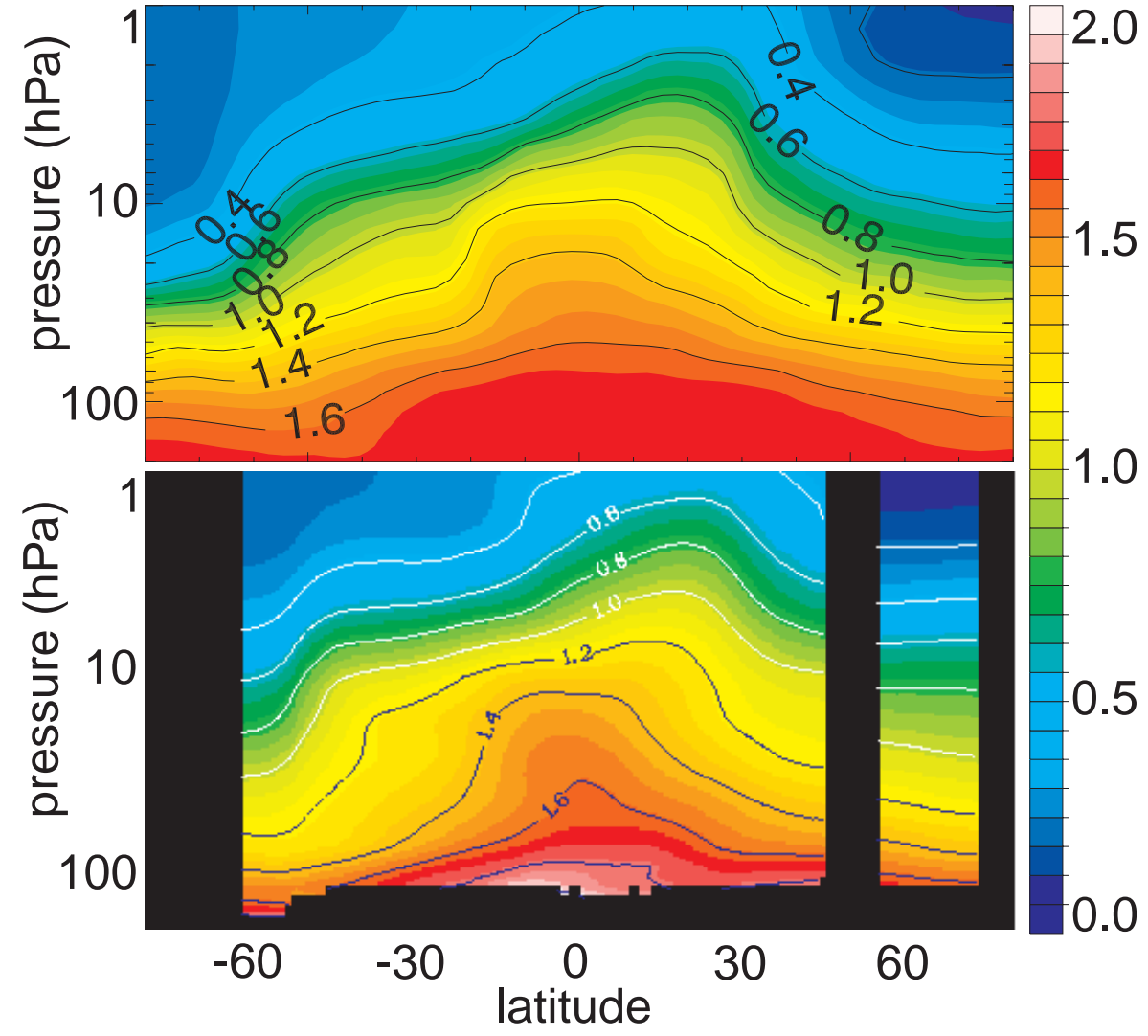

Fig. 14. Zonal mean $\mathrm{CH}_{4}$ mixing ratios (ppmv) on 23 August 2000, simulated by MAECHAM5/MESSy (top) and observed by HALOE (bottom).
5, 961-1006, 2005

Stratospheric temperatures and transport in a nudged GCM

M. K. van Aalst et al.

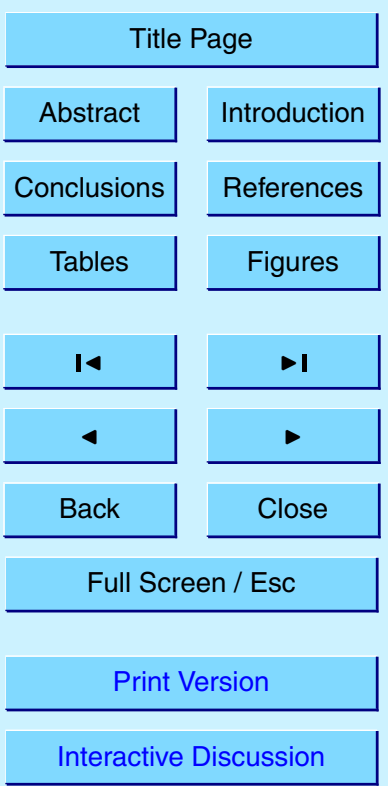

EGU 


\section{ACPD}

5, 961-1006, 2005

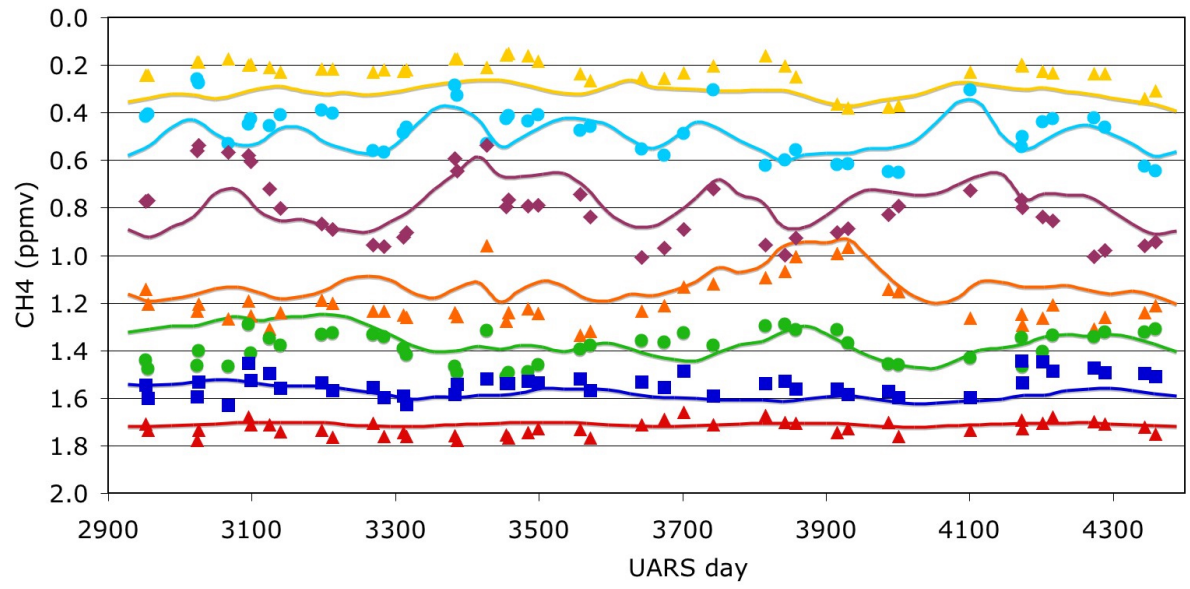

Fig. 15. $\mathrm{CH}_{4}$ concentrations at $20^{\circ} \mathrm{N}$ (ppmv) versus time (days). Solid lines represent monthly mean zonal mean MAECHAM5/MESSy $\mathrm{CH}_{4}$ concentrations at, from top to bottom, $0.4 \mathrm{hPa}$ (yellow), $1.3 \mathrm{hPa}$ (blue), $4 \mathrm{hPa}$ (purple), $10 \mathrm{hPa}$ (orange), $24 \mathrm{hPa}$ (green), $54 \mathrm{hPa}$ (blue), and $70 \mathrm{hPa}$ (red). The marks represent HALOE measurements, in the same colors as the corresponding model levels. Time is given in UARS days; day 2900 corresponds to 20 August 1999; day 4300 to 20 June 2003.
Stratospheric temperatures and transport in a nudged GCM

M. K. van Aalst et al.

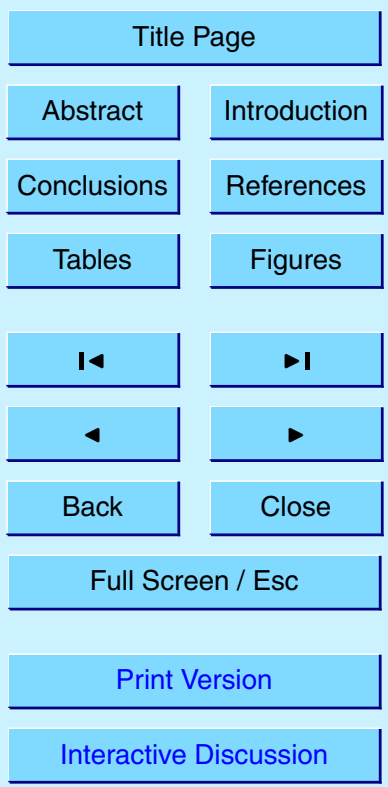




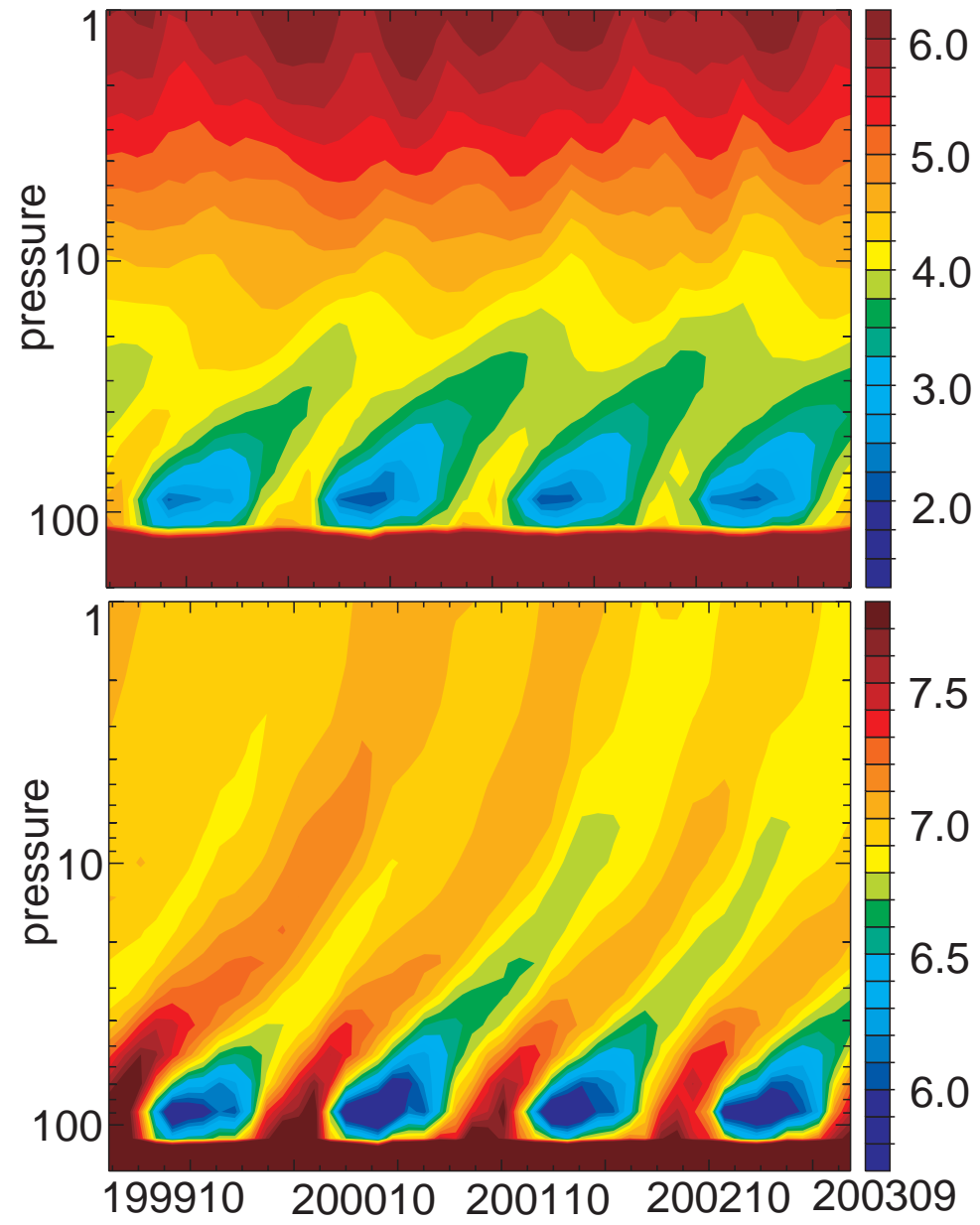

Fig. 16. Time series of MAECHAM5/MESSy simulated zonal mean monthly mean equatorial concentrations of water (top) and total water $\left(2^{*} \mathrm{CH}_{4}+\mathrm{H}_{2} \mathrm{O}\right.$, bottom) (ppmv).
ACPD

5, 961-1006, 2005

Stratospheric temperatures and transport in a nudged GCM

M. K. van Aalst et al.

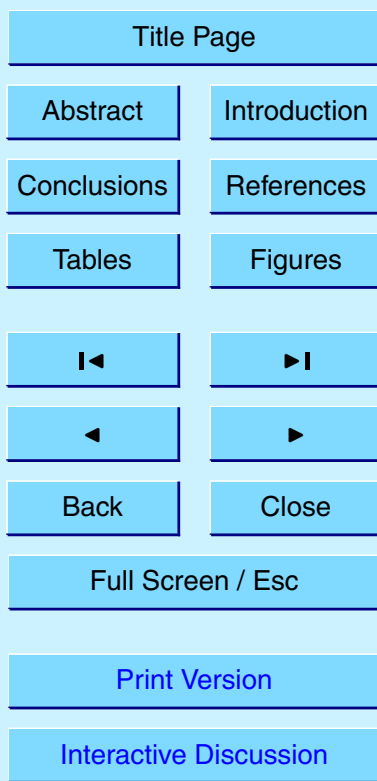

EGU 


\section{ACPD}

5, 961-1006, 2005
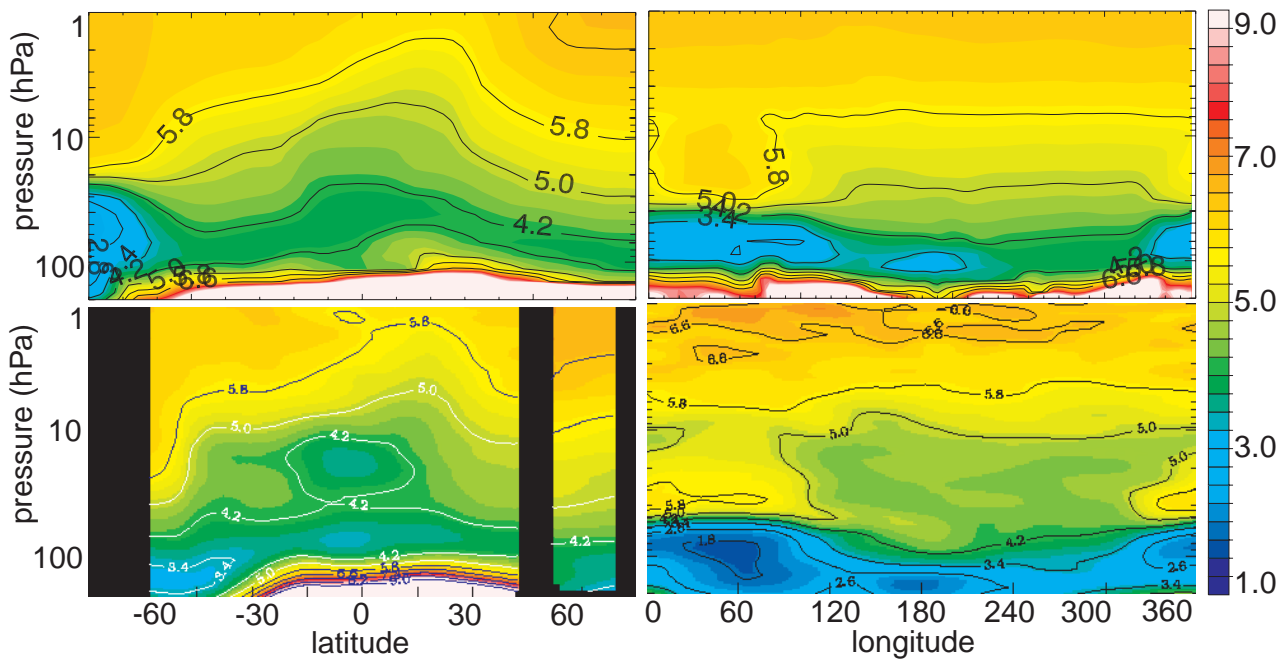

Fig. 17. $\mathrm{H}_{2} \mathrm{O}$ mixing ratios (ppmv); on 23 August 2000 (zonal mean left), and on 3 November 2000 (at $74^{\circ} \mathrm{S}$, right), simulated by MAECHAM5/MESSy (top) and observed by HALOE (bottom).

Stratospheric temperatures and transport in a nudged GCM

M. K. van Aalst et al.

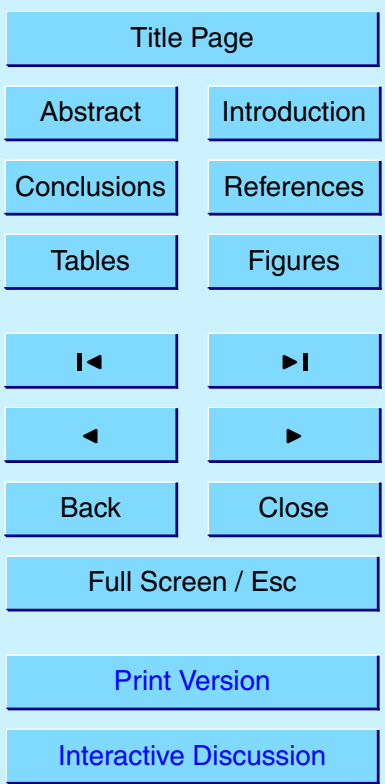

